\title{
Polyphenols Extracted from Shanxi-Aged Vinegar Inhibit Inflammation in LPS-Induced RAW264.7 Macrophages and ICR Mice via the Suppression of MAPK/NF-KB Pathway Activation
}

\author{
Peng Du ${ }^{1,2}$, Jia Song $1,2, * \mathbb{C}$, Huirui Qiu ${ }^{1,2}$, Haorui Liu ${ }^{1}$, Li Zhang ${ }^{1}$, Junhan Zhou ${ }^{1}$, Shengping Jiang ${ }^{3}$, Jinyu Liu ${ }^{3}$, \\ Yu Zheng ${ }^{1,2, *}$ and Min Wang ${ }^{1,2, *(1)}$ \\ 1 Key Laboratory of Industrial Fermentation Microbiology (Tianjin University of Science and Technology), \\ Ministry of Education, Tianjin 300457, China; dp9298@163.com (P.D.); 13199573023@139.com (H.Q.); \\ 13205498828@163.com (H.L.); zl15774205290@163.com (L.Z.); zhoujh8877@163.com (J.Z.) \\ 2 State Key Laboratory of Food Nutrition and Safety, Tianjin Engineering Research Center of Microbial \\ Metabolism and Fermentation Process Control, College of Biotechnology, \\ Tianjin University of Science \& Technology, Tianjin 300457, China \\ 3 Research Center for Modern Analysis Techniques, Tianjin University of Science \& Technology, \\ Tianjin 300457, China; jiangshengping@tust.edu.cn (S.J.); liujy@tust.edu.cn (J.L.) \\ * Correspondence: tjsongjia@tust.edu.cn (J.S.); yuzheng@tust.edu.cn (Y.Z.); minw@tust.edu.cn (M.W.); \\ Tel.: +86-022-60601256 (J.S.); +86-022-60601256 (Y.Z.); +86-022-60600045 (M.W.)
}

check for updates

Citation: Du, P.; Song, J.; Qiu, H.; Liu, H.; Zhang, L.; Zhou, J.; Jiang, S.; Liu, J.; Zheng, Y.; Wang, M. Polyphenols Extracted from Shanxi-Aged Vinegar Inhibit Inflammation in LPS-Induced RAW264.7 Macrophages and ICR Mice via the Suppression of MAPK/NF-KB Pathway Activation. Molecules 2021, 26, 2745. https:// doi.org/10.3390/molecules26092745

Academic Editors:

Ryszard Amarowicz and Adriano Costa de Camargo

Received: 9 April 2021

Accepted: 4 May 2021

Published: 7 May 2021

Publisher's Note: MDPI stays neutral with regard to jurisdictional claims in published maps and institutional affiliations.

Copyright: () 2021 by the authors. Licensee MDPI, Basel, Switzerland. This article is an open access article distributed under the terms and conditions of the Creative Commons Attribution (CC BY) license (https:// creativecommons.org/licenses/by/ $4.0 /)$.

\begin{abstract}
Shanxi-aged vinegar, a traditional Chinese grain-fermented food that is rich in polyphenols, has been shown to have therapeutic effects on a variety of diseases. However, there has been no comprehensive evaluation of the anti-inflammatory activity of polyphenols extracted from Shanxiaged vinegar (SAVEP) to date. The anti-inflammatory activities of SAVEP, both in RAW 264.7 macrophages and mice, were extensively investigated for the potential application of SAVEP as a novel anti-inflammatory agent. In order to confirm the notion that polyphenols could improve inflammatory symptoms, SAVEP was firstly detected by gas chromatography mass spectrometry (GC-MS). In total, 19 polyphenols were detected, including 12 phenolic acids. The study further investigated the protective effect of SAVEP on lipopolysaccharide-induced inflammation in RAW264.7 macrophages and ICR mice. The results showed that compared with those of the model group, SAVEP could remarkably recover the inflammation of macrophage RAW264.7 and ICR mice. SAVEP can normalise the expression of related proteins via the suppression of MAPK/NF- $\mathrm{B}$ pathway activation, inhibiting the expression of iNOS and COX-2 proteins, and consequently the production of inflammatory factors, thus alleviating inflammatory stress. These results suggest that SAVEP may have a potential function against inflammation.
\end{abstract}

Keywords: Shanxi-aged vinegar; polyphenol extract; anti-inflammation; RAW264.7 macrophages; mice

\section{Introduction}

Shanxi-aged vinegar (SAV) is a traditional Chinese fermented food that contains many active compounds [1]. The components, produced during the brewing of SAV, such as organic acids, sugar, peptides, amino acids, polyphenols, melanoidins, and flavour substances, all have health-related and therapeutic effects [2]. Among the functional molecules in SAV, polyphenol is an important antioxidant compound that has been identified. SAV contains a variety of polyphenols, including gallic acid, tannins, ferulic acid, catechin, quercetin, anthocyanins, p-coumaric acid, and resveratrol, which can prevent several diseases, such as cardiovascular diseases, hepatic damage, neurodegenerative diseases, cancer, and hyperlipemia [3,4]. Polyphenols have significant antioxidant effects, but their anti-inflammatory effects are also worthy of attention [5].

Inflammation is an important physiological response of the host against pathogenic infection or tissue damage, which plays a key role in infections [6], chronic diseases [7], 
cardiovascular diseases [8], and various human cancers [9,10]. Immune cells (such as macrophages) initiate an inflammatory response by increasing the production of nitric oxide (NO), reactive oxygen species (ROS), and inflammatory cytokines [11]. Low-level inflammation is necessary and beneficial to the human body [12], but excessive inflammation can lead to many diseases, such as asthma, rheumatoid arthritis, and atherosclerosis [13]. Drug therapy for inflammation is a traditionally effective method, but drug therapy often has side effects. Dexamethasone is an effective anti-inflammatory drug, but long-term use can lead to glucocorticoid withdrawal syndrome and digestive complications [14]. Therefore, anti-inflammatory ingredients derived from natural products are a good choice.

Lipopolysaccharide (LPS) is an effective stimulant for the release of pro-inflammatory cytokines and NO that induce vasodilation and increase vascular permeability, which can lead to cardiovascular dysfunction, lung function damage, acute renal insufficiency, septic shock, and even death [15]. LPS-induced cell damage and animal inflammation are common models of inflammation. The composition and mechanism of polyphenols in SAV are complex. The anti-inflammatory activity of polyphenols involves different targets: these targets can be subdivided into arachidonic acid-dependent pathways, such as cyclooxygenase (COX) inhibition, lipoxygenase inhibition, and phospholipase A2 inhibition. Within the arachidonic acid-independent pathways, nitric oxide synthase (NOS), nuclear factor $\mathrm{\kappa B}(\mathrm{NF}-\mathrm{kB})$, and NSAID activated gene-1 (NAG-1) are the targets of polyphenol. Moreover, polyphenols also affect the production of T helper type 1 and 2 cytokines [16,17].

In the arachidonic acid-dependent polyphenol pathway, part of its role is related to its antioxidant activity. This relationship has been studied for more than 20 years, and some papers presented data on the inhibition of COX-1 and COX-2 at transcriptional and enzymatic levels. However, according to recent studies, it is clear that polyphenols act on both pathways as antioxidants and modulators of gene expression. The type of activity can be distinguished. COX inhibition may explain the anti-inflammatory effect of reduced prostaglandin synthesis in the arachidonic pathway [17,18].

Epigallocatechin gallate (EGCG), a polyphenol in green tea, downregulates COX2 in human mammary epithelial cells stimulated by 12-o-tetradecylphobos-13-acetate (TPA). It is suggested that the underlying mechanism is a decrease in the activation of extracellular signal-regulated protein kinase and p38 mitogen-activated protein kinases; upstream enzymes regulate the expression of COX-2. EGCG and green tea extract inhibit interleukin (IL)-1 $\beta$-dependent inflammatory signal transduction and IL-8 gene expression via the NF-kB-dependent pathway. The authors suggest that the application of EGCG and its related compounds may represent a new pharmacological strategy for regulating the inflammatory response of the NF- $\mathrm{KB}$ pathway $[19,20]$. Different polyphenols affect different intracellular signalling pathways. In addition to the type of polyphenols, the disease and the stimulus applied are also important factors. Interactions and synergies between different polyphenols also affect different intracellular signalling pathways [21].

Even though polyphenols are beneficial to human health, the regulation mechanism of polyphenol extracts in vinegar in relation to inflammatory stress metabolism remains unknown. In order to further analyse the anti-inflammatory activity of SAVEP, firstly, polyphenols in SAVEP were isolated and quantitatively detected based on previous work; then, we further investigated the anti-inflammatory effects of SAVEP and the anti-inflammatory mechanism in LPS-induced RAW264.7 macrophages and ICR mice.

\section{Results}

\subsection{Analysis of SAVEP}

The determination of the total antioxidant activity of polyphenol extraction-A, polyphenol extraction-B, and polyphenol extraction- $\mathrm{C}$ was carried out using the DPPH, ABTS and FRAP methods, with ranges of $0.16 \pm 0.02-1.36 \pm 0.21 \mathrm{mmol}$ TEAC/L, $1.61 \pm 0.20-3.43$ $\pm 0.13 \mathrm{mmol}$ TEAC/L, and $0.22 \pm 0.03-1.06 \pm 0.06 \mathrm{mmol}$ TEAC/L, respectively (Figure S1). The order of total antioxidant activity identified by the three methods is polyphenol extraction-A > polyphenol extraction- $\mathrm{C}>$ polyphenol extraction- $\mathrm{B}$. The total antioxidant 
activity of the polyphenol extraction-A sample was the highest, and it was significantly different from the other samples $(p<0.05)$. It was shown that polyphenol extractionA had strong free radical scavenging and reducing ability, and it exhibited the highest antioxidant activity among the three polyphenol extract samples. Our previous results suggest that antioxidant activity is positively correlated with anti-inflammatory effects [22]. Therefore, polyphenol extraction-A was selected as the most appropriate SAVEP in the subsequent research.

Based on the GC-MS analysis and our previous work, a total intensity chromatogram image of SAVEP is shown in Figure 1. Referring to the quantitative method of GCMS experiment conducted by Rabah [23], we chose the relative quantitative method to quantify the detected polyphenols. Our study showed a total of 703 peaks in the sample. Relative to those in the NIST 11 database, 19 polyphenols, including 12 phenolic acids, were found. Specific corresponding results are shown in Supplementary Table S1. The top five polyphenols by concentration are as follows: hydroferulic acid, vanillic acid, ferulic acid, 4-coumaric acid, and 4-hydroxybenzoic acid. The names of the five polyphenols corresponding to the polyphenol derivatives in Table S1 are (1) benzenepropanoic acid, 3-methoxy-4 [(trimethylsilyl)oxy]-, trimethylsilyl ester; (2) benzoic acid, 3-methoxy-4- [(trimethylsilyl)oxy]-, trimethylsilyl ester; (3) trimethylsilyl 3-methoxy-4(trimethylsilyloxy)cinnamate, cinnamic acid; (4) p-(trimethylsiloxy)-, trimethylsilyl ester; and (5) benzoic acid, 4- [(trimethylsilyl)oxy]-, trimethylsilyl ester.

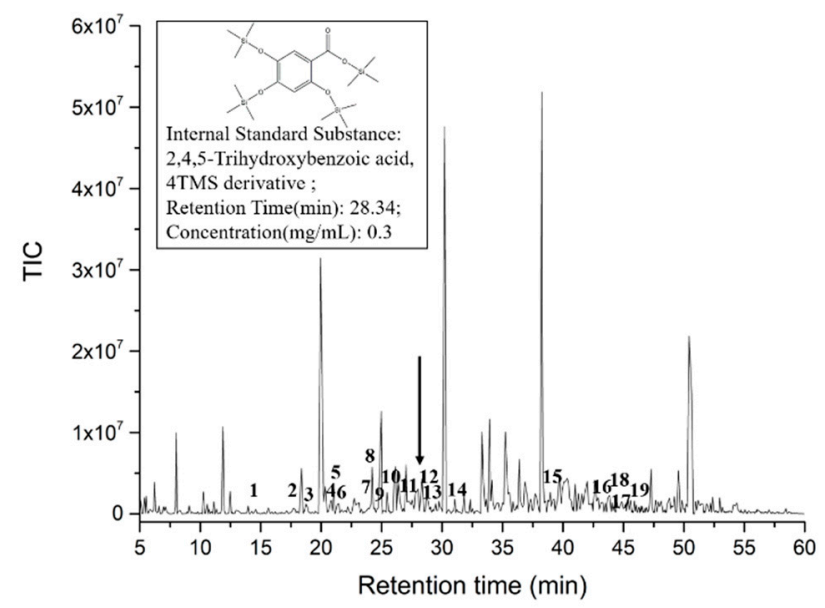

Figure 1. Total intensity chromatogram (TIC) images of SAVEP.

\subsection{Effects of Different SAVEP Concentrations on Cell Viability and Dose Selection}

Cell viability studies were conducted at five different SAVEP concentrations $(100,200$, 400,600 , and $800 \mu \mathrm{g} / \mathrm{mL}$ ). The maximum cytotoxic effect was observed at concentrations of 600 and $800 \mu \mathrm{g} / \mathrm{mL}$, and the minimum was found at $400 \mu \mathrm{g} / \mathrm{mL}$ (Figure 2A). No significant difference was observed among concentrations of 100,200 , and $400 \mu \mathrm{g} / \mathrm{mL}$ or between RAW 264.7 macrophages and the control group at these three concentrations. Therefore, SAVEP concentrations in the range of $100-400 \mu \mathrm{g} / \mathrm{mL}$ had no effect on cell growth.

As an important indicator of cellular inflammation, TNF- $\alpha$ can reflect the degree of inflammation. Figure 2B shows that SAVEP can effectively alleviate the inflammation induced by LPS, and each dose group had significant difference compared with the control group $(p<0.05)$. When the dose range was at $100-400 \mu \mathrm{g} / \mathrm{mL}$, (concentration of TNF$\alpha: 150.41 \pm 5.95-135.19 \pm 6.48 \mathrm{pg} / \mathrm{mL}$ ), the expression of TNF- $\alpha$ quantity showed a declining trend. When the concentration was more than $600 \mu \mathrm{g} / \mathrm{mL}$ (concentration of TNF- $\alpha$ : $136.17 \pm 7.05 \mathrm{pg} / \mathrm{mL}$ ), the TNF- $\alpha$ content slightly increased because the increase in SAVEP concentration simultaneously protects and damages cells (Figure 2A). Therefore, 200 and $400 \mu \mathrm{g} / \mathrm{mL}$ were chosen as the low- and high-dose concentrations, respectively, for the next study. 

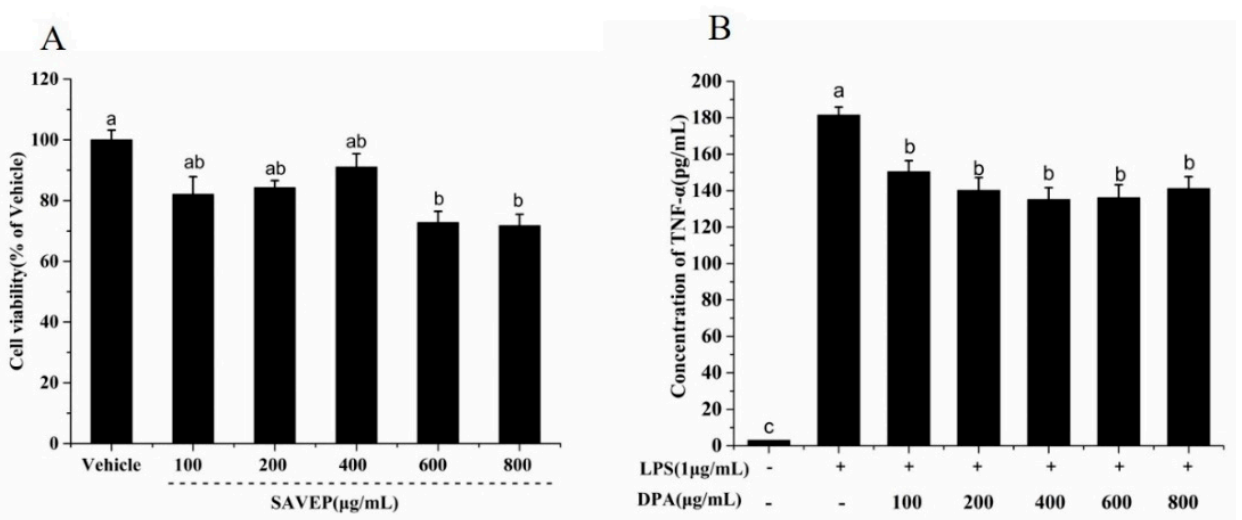

Figure 2. Screening of anti-inflammatory activity of the SAVEP. (A) Effects of different concentrations of SAVEP on cell viability. (B) Screening of anti-inflammatory activity concentration of SAVEP. Statistical analysis was performed using a one-way ANOVA with Tukey's test. Data represent the mean $\pm \mathrm{SD}(n=6)$. Different letters represent significant differences between groups $(p<0.05)$.

\subsection{Effects of SAVEP on LPS-Induced Inflammatory Cell Morphology}

The cell surface of the vehicle group was smooth without shrinkage, and that in the model group induced by LPS was morphologically heterogeneous with an uneven surface. The cells treated with SAVEP of different concentrations showed similar morphology to those of the vehicle group with a few pits and no atypia. These results show that SAVEP effectively alleviated the inflammatory stress caused by LPS and had a protective effect on cell morphology (Figure S2).

\subsection{Effects of SAVEP on LPS-Induced Inflammatory Cell Nucleus Morphology}

In addition to cell morphology, DNA damage is also an important indicator of cell health. LPS was used to induce inflammation on RAW264.7 cells, which were finally stained with DNA dye Hoechst 33,342 to reflect the degree of cell DNA damage. Figure 3 shows that under a fluorescence microscope, nuclear chromatin condensation or nuclear fragmentation gradually occurred in the RAW264.7 cells of the model group. Compared with the vehicle group $(100 \pm 6.28 \%)$, the value of blue fluorescence significantly increased by $254.24 \%$ in the model group $(354.239 \pm 36.57 \%)(p<0.05)$. The nucleus morphologies in the SAVEP groups were significantly altered compared with that of the model group, and nucleus apoptosis was alleviated. The fluorescence intensity was reduced by $170.14 \%$ in the HD group $(131.13 \pm 18.86 \%)$ compared with the model group $(p<0.05)$. These results show that SAVEP at concentrations of 200 and $400 \mu \mathrm{g} / \mathrm{mL}$ could effectively protect the nucleus with inflammatory damage.

\subsection{Effects of SAVEP on LPS-Induced Inflammatory Cell Mitochondrial Membrane Potential}

The change in JC-1 from red fluorescence to green fluorescence can be used as an indicator of early apoptosis [24]. Figure $4 \mathrm{~A}$ shows the fluorescence intensity observed under a fluorescence microscope. The green fluorescence intensity in the model group was increased compared with that in the vehicle group, whereas the red fluorescence intensity was decreased. The intracellular green fluorescence intensity was reduced in the SAVEPtreated groups compared with that in the model group, whereas the red fluorescence intensity was enhanced. The change in the HD group was more significant than that in the LD group. As shown in Figure 4B, the ratio of red/green fluorescence in the model group $(52.53 \% \pm 10.11 \%)$ was significantly reduced by $50.29 \%$ compared with that in the vehicle group $(105.67 \% \pm 12.23 \%)(p<0.05)$, and the mitochondrial membrane potential was significantly reduced, resulting in severe cell apoptosis. The ratio of red/green fluorescence in the HD group $(92.9 \% \pm 13.31 \%)$ was increased by $76.85 \%$ compared with that in the model group $(p<0.05)$, indicating that HD could significantly increase mitochondrial membrane potential and rejuvenate injured cells. 

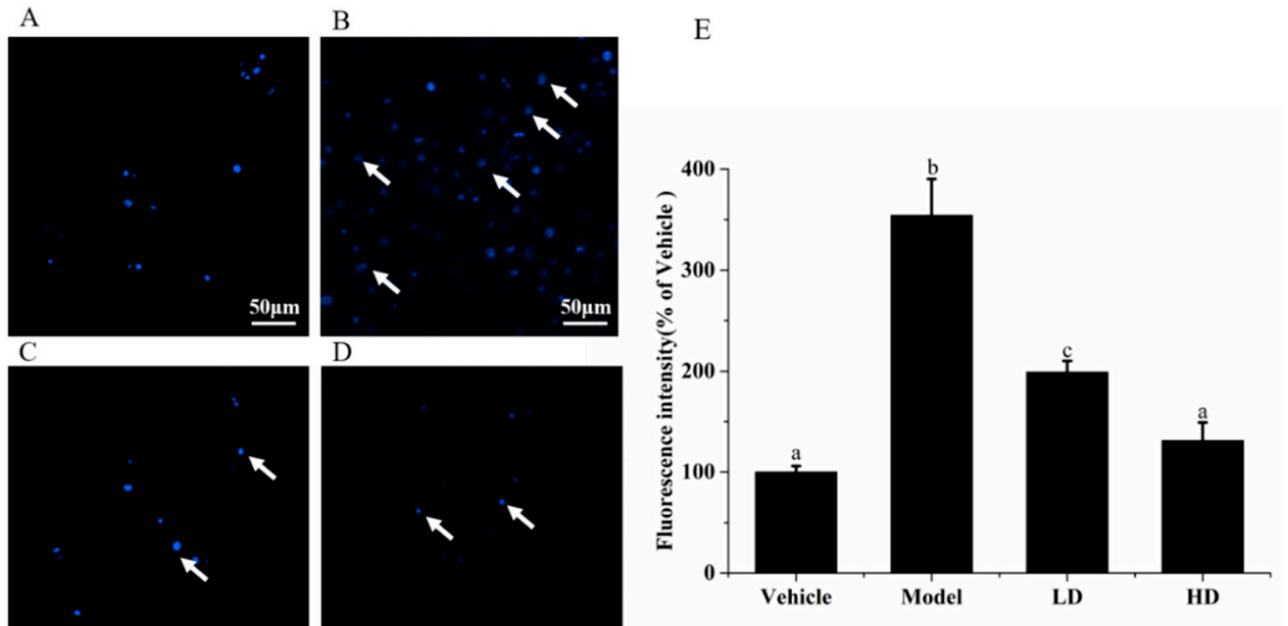

Figure 3. Effects of SAVEP on RAW264.7 cell nuclear morphology of LPS-induced inflammatory injury with fluorescence electron microscope. (A) Vehicle group. (B) Model group. (C) LD group (D) HD group. (E) Fluorescence intensity (of vehicle). Statistical analysis was performed using a one-way ANOVA with Tukey's test. Data represent the mean $\pm \operatorname{SD}(n=6)$. Different letters represent significant differences between groups $(p<0.05)$.
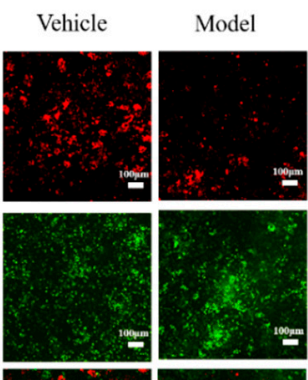
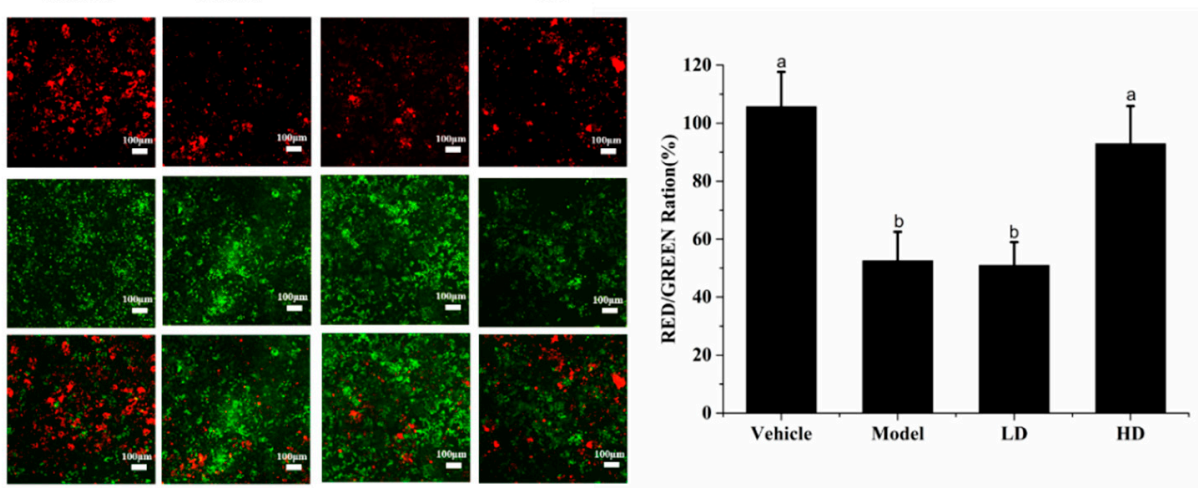

Figure 4. Effects of SAVEP on RAW264.7 cell mitochondrial membrane potential (MMP) of LPSinduced inflammatory injury. (A) Fluorescence intensity was observed by fluorescence microscope. (B) Fluorescence intensity of red/green ratio. Statistical analysis was performed using a one-way ANOVA with Tukey's test. Data represent the mean $\pm \mathrm{SD}(n=6)$. Different letters represent significant differences between groups $(p<0.05)$. A larger version of $(\mathbf{A})$ is shown in Figure S3.

\subsection{Effects of SAVEP on LPS-Induced Inflammatory Cell Apoptosis}

Annexin V/PI staining was used to detect apoptosis. As shown in Figure 5, the apoptosis rate of LPS-induced cells significantly increased by $54.70 \pm 6.80 \%(p<0.05)$ compared with that of the vehicle group $(37.48 \pm 2.70 \%)$. However, compared with that of the model group, the apoptosis rate of SAVEP treatment gradually decreased with the increase in SAVEP concentration, thereby indicating a dose-dependent pattern. Notably, the SAVEP of $400 \mu \mathrm{L} / \mathrm{mL}$ had the best protective effect and reduced the apoptosis rate of damaged hepatocytes to $38.42 \pm 1.50 \%(p<0.05)$. Therefore, comprehensive apoptosis detection indicators showed that SAVEP could alleviate the inflammatory cell injury induced by LPS and that it has a protective effect on inflammatory cells. 

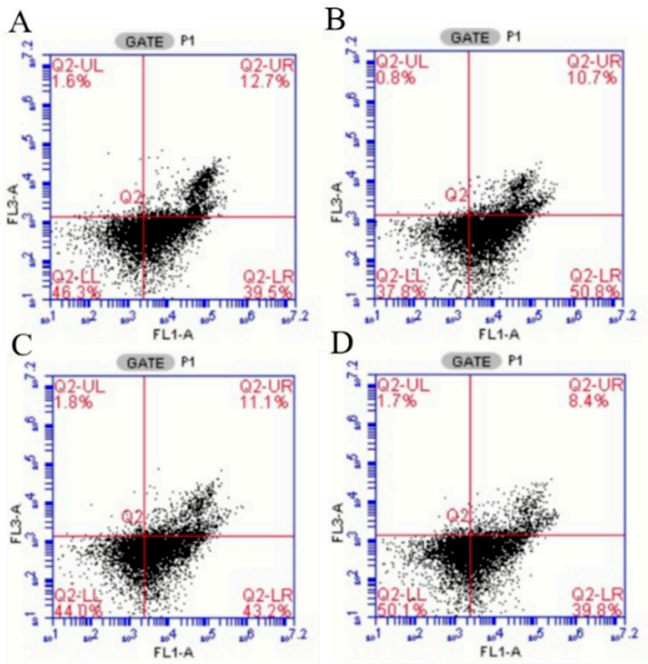

\section{E}

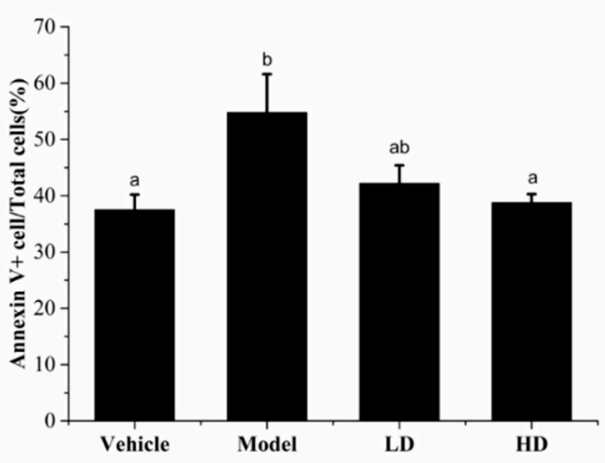

Figure 5. RAW264.7 cells were stained with annexin V-FITC and propidium iodide (PI) as detected by flow cytometer. (A) Vehicle group. (B) Model group. (C) LD group. (D) HD group. Statistical analysis was performed using a one-way ANOVA with Tukey's test. Data represent the mean \pm SD $(n=6)$. Different letters represent significant differences between groups $(p<0.05)$.

\subsection{Effects of SAVEP on LPS-Induced Inflammatory Cytokine Levels}

IL-1 $\beta$, IL-6, IL-18, MCP-1, and NO are typical inflammatory markers. Table 1 shows that all five inflammatory indicators in the model group increased to varying degrees and showed significant differences compared with those in the vehicle group, except IL$6(p<0.05)$. After SAVEP treatment, the inflammatory stress response of the cells was alleviated to a certain extent. The values of IL-1, IL-6, IL-18, and MCP-1 in the model group were $4.14 \pm 0.64,2.78 \pm 0.20,21.73 \pm 0.60$, and $3.06 \pm 0.20 \mathrm{pg} / \mathrm{mL}$, respectively, and that of NO was $5.30 \times 10^{-3} \pm 1.34 \times 10^{-4} \mu \mathrm{mol} / \mathrm{L}$. Compared with those in the model group, all indicators in the HD group showed a downward trend; the differences for IL-1 $\beta(2.53 \pm 0.44 \mathrm{pg} / \mathrm{mL})$, IL-6 $(2.27 \pm 0.26 \mathrm{pg} / \mathrm{mL})$, and IL-18 $(18.46 \pm 1.21 \mathrm{pg} / \mathrm{mL})$ were significant $(p<0.05)$, and the differences for IL-1 $\beta(2.85 \pm 0.35 \mathrm{pg} / \mathrm{mL})$ in the LD group with the model group were significant $(p<0.05)$. These results show that SAVEP exhibits a dose-dependent influence on relieving inflammatory stress response and that a high SAVEP concentration has a significant effect on repairing cellular inflammatory damage caused by LPS.

Table 1. Effects of SAVEP on inflammatory cytokines levels.

\begin{tabular}{cccccc}
\hline & Vehicle & Model & LD & HD & $p$-Value \\
\hline IL-1 $\beta(\mathrm{pg} / \mathrm{mL})$ & $2.31 \pm 0.20^{\mathrm{a}}$ & $4.14 \pm 0.64^{\mathrm{b}}$ & $2.85 \pm 0.35^{\mathrm{a}}$ & $2.53 \pm 0.44^{\mathrm{a}}$ & 0.004 \\
IL-6(pg/mL) & $2.46 \pm 0.13^{\mathrm{ab}}$ & $2.78 \pm 0.20^{\mathrm{b}}$ & $2.51 \pm 0.11^{\mathrm{ab}}$ & $2.26 \pm 0.26^{\mathrm{a}}$ & 0.049 \\
$\mathrm{IL}-18(\mathrm{pg} / \mathrm{mL})$ & $17.80 \pm 0.51^{\mathrm{a}}$ & $21.73 \pm 0.60^{\mathrm{b}}$ & $20.41 \pm 0.49^{\mathrm{b}}$ & $18.46 \pm 1.21^{\mathrm{a}}$ & 0.008 \\
$\mathrm{MCP}-1(\mathrm{pg} / \mathrm{mL})$ & $2.21 \pm 0.20^{\mathrm{a}}$ & $3.06 \pm 0.20^{\mathrm{b}}$ & $2.87 \pm 0.35^{\mathrm{b}}$ & $2.75 \pm 0.25^{\mathrm{ab}}$ & 0.019 \\
$\mathrm{NO}(\mu \mathrm{mol} / \mathrm{L})$ & $4.60 \times 10^{-3} \pm$ & $5.30 \times 10^{-3} \pm$ & $5.39 \times 10^{-3} \pm$ & $5.20 \times 10^{-3} \pm$ & 0.033 \\
\hline
\end{tabular}

Statistical analysis was performed using a one-way ANOVA with Tukey's test. Data are presented as mean $\pm \operatorname{SD}(n=6)$. Values in the same row with different letters are significantly different $(p<0.05)$.

\subsection{Effects of SAVEP on LPS-Induced Inflammatory Cell Inflammatory Protein Expression}

P-p38, p38, JNK, P-JNK, ERK1/2, P-ERK1/2, iNOS, and COX-2 expression levels of RAW264.7 were analysed by Western blot analysis, and the results are shown in Figure 6. Relative to those in the vehicle group, the expression levels of iNOS and COX-2 of the model group were significantly increased by $94.92 \%, 607.14 \%$, and $83.61 \%$, respectively (all $p<0.05)$. The values of P-p38/p38 (37.84\%), P-JNK/JNK (225.81\%), and P-ERK1/2/ 
ERK1/2(151.77\%) increased significantly in the model group compared with those in the vehicle group. This result indicates that LPS causes the inflammatory reaction and further increases the expression of inflammation-related proteins. Relative to those in the model group, the levels of P-p38/p38, P-JNK/JNK, and P-ERK1/2/ ERK1/2 were significantly decreased in the $\operatorname{LD}(65.67 \%, 54.46 \%$, and $62.18 \%)$ and $\operatorname{HD}(67.65 \%, 59.41 \%$, and $64.00 \%)$ groups (all $p<0.05)$, and iNOS was significantly decreased in the LD $(42.42 \%)$ and HD $(44.44 \%)$ groups (all $p<0.05)$. However, no significant change was observed in COX2 expression in the LD and HD groups $(p>0.05)$. Thus, SAVEP supplementation could significantly downregulate the expression of iNOS, COX-2, p38, JNK, and ERK1/2 proteins.
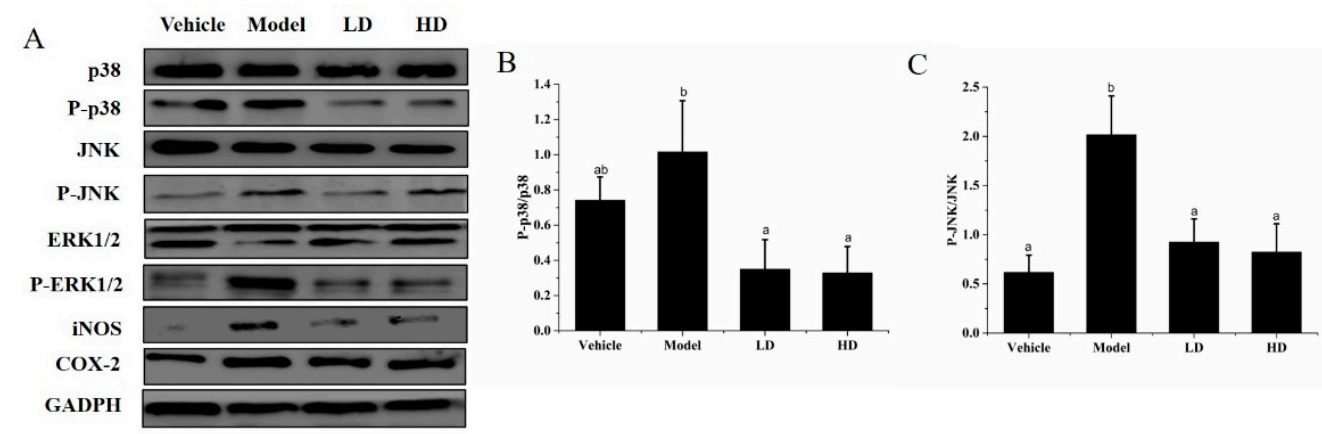

$\mathrm{D}$

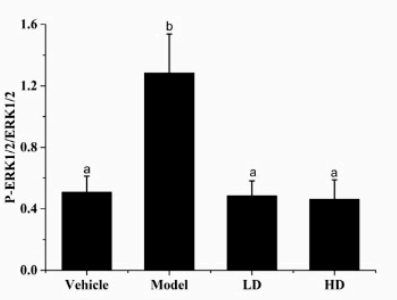

$\mathrm{E}$

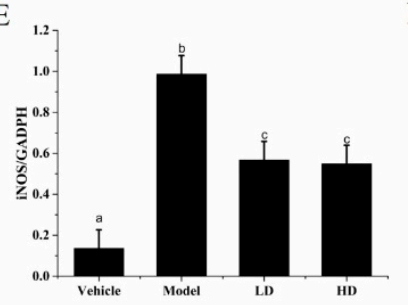

$\mathrm{F}$

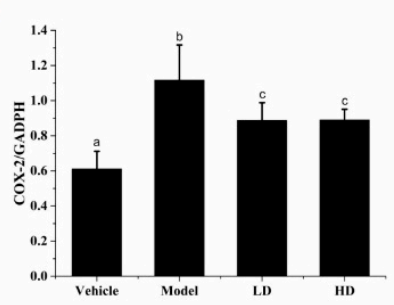

Figure 6. Effect of SAVEP on inflammatory protein expression in inflammatory-damaged RAW264.7 cells. (A) Expression levels of proteins were detected through Western blot analysis. (B) Quantitative analysis of P-p38/p38 protein level. (C) Quantitative analysis of P-JNK/JNK protein level. (D) Quantitative analysis of P-ERK1/2/ERK1/2 protein level. (E) Quantification of iNOS protein expression. (F) Quantification of the COX-2 protein expression. Statistical analysis was performed using a one-way ANOVA with Tukey's test. Data represent the mean $\pm \operatorname{SD}(n=6)$. Different letters represent significant differences between groups $(p<0.05)$.

\subsection{Effects of SAVEP on Inflammatory Factor Levels in Mice}

Changes in blood indexes are the most direct way to reflect the degree of inflammation in the body. Compared with those in the vehicle group, COX-2, CRP, NOS, IgM, IL- $1 \beta$, IL-6, $\mathrm{NO}$, and TNF- $\alpha$ index levels in the model group were increased by $72.99 \%, 28.25 \%, 43.21 \%$, $39.41 \%, 101.42 \%, 11.56 \%, 100.45 \%$, and $23.43 \%$ (all $p<0.05$ ), respectively. However, IL-10, $\operatorname{IgA}$, and IgG were decreased by $19.21 \%, 22.61 \%$ and $68.67 \%$ (all $p<0.05$ ), respectively.

Compared with those in the model group, the indexes of COX-2, CRP, NOS, IgM, IL-1 $\beta$, IL-6, NO, and TNF- $\alpha$ in the PC, LD, and HD groups presented a downward trendthe indexes in the HD group were increased by $38.41 \%, 22.48 \%, 22.49 \%, 19.60 \%, 45.43 \%$, $12.04 \%, 47.62 \%$, and $19.92 \%(p<0.05)$, respectively. While the indexes of IL-10, IgA, and IgG presented an upward trend in the PC, LD, and HD groups, the indexes in the HD group were decreased by $14.41 \%, 25.11 \%$, and $176.92 \%(p<0.05)$, respectively (Figure 7 ). These results show that LPS-induced mice produced an inflammatory stress response, leading to a change in related inflammatory indicators. SAVEP intervention normalised the level of related inflammatory indicators, indicating that SAVEP can relieve the inflammatory stress response in mice and play a certain protective role in the body of mice. 
A

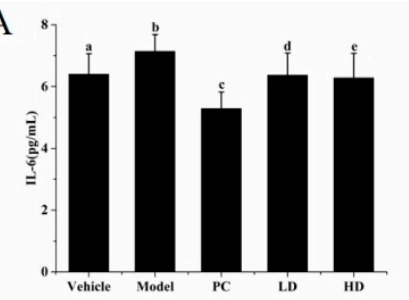

D

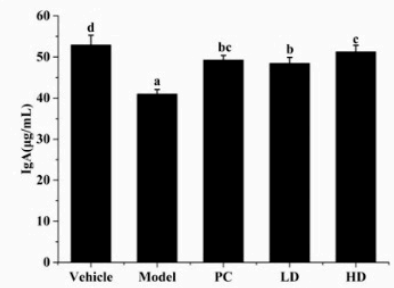

G

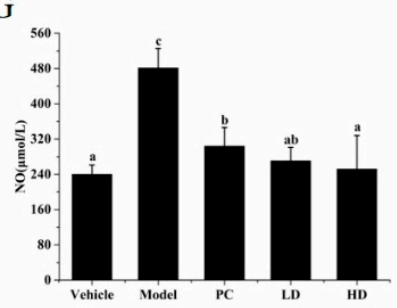

$\mathrm{B}$

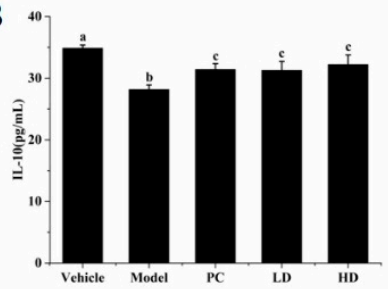

E

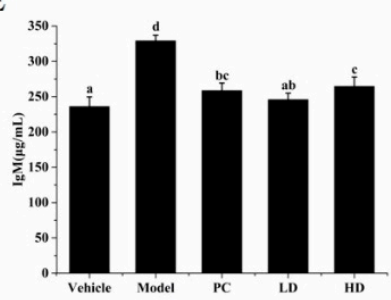

$\mathrm{H}$

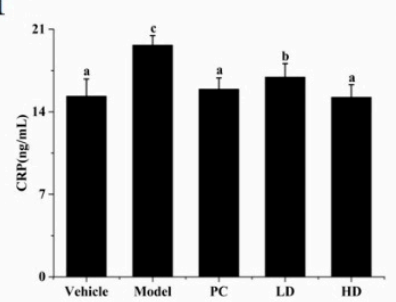

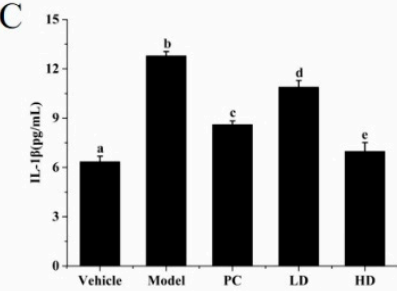

$\mathrm{F}$

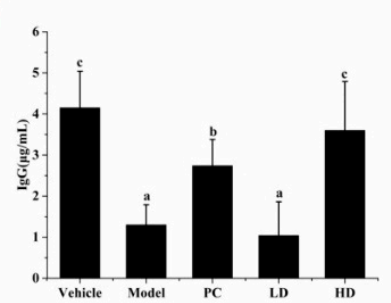

I

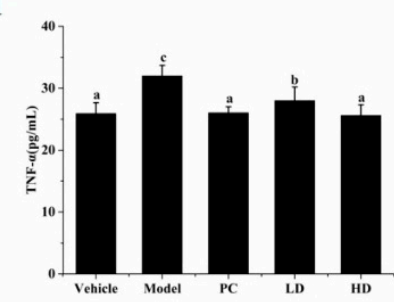

$\mathrm{J}$

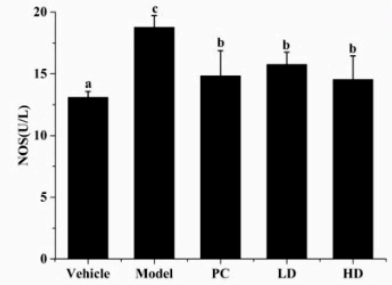

$\mathrm{K}$

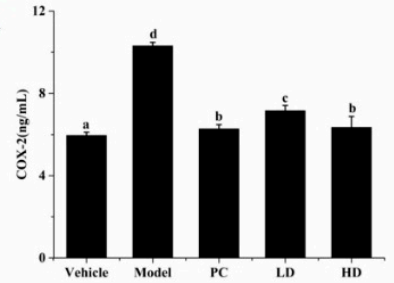

Figure 7. Effects of SAVEP on serum indexes in mice. Quantitative analysis of IL-6 (A), IL-10 (B), $\operatorname{IL}-1 \beta(\mathbf{C}), \operatorname{IgA}(\mathbf{D}), \operatorname{IgM}(\mathbf{E}), \operatorname{IgG}(\mathbf{F}), \mathrm{NO}(\mathbf{G}), \mathrm{CRP}(\mathbf{H}), \operatorname{TNF}-\alpha(\mathbf{I}), \operatorname{NOS}(\mathbf{J})$, and COX-2 (K). Statistical analysis was performed using a one-way ANOVA with Tukey's test. Data represent the mean $\pm \mathrm{SD}$ $(n=6)$. Different letters represent significant differences between groups $(p<0.05)$.

\subsection{Effects of SAVEP on Inflammatory Protein Expression in LPS-Induced Inflammatory Mouse Liver}

NF- $\mathrm{B}$, P-NF- $\mathrm{B}$, iNOS, and COX-2 levels in mouse liver were analysed by Western blot, and the results are shown in Figure 8. The P-NF- $\mathrm{kB} / \mathrm{NF}-\mathrm{kB}$ values of the model group significantly decreased by $41.49 \%$ compared with those of the vehicle group (all $p<0.05$ ). The iNOS and COX-2 values of the model group significantly increased by $78.87 \%$ and $19.74 \%$, respectively, compared with those of the vehicle group (all $p<0.05$ ). The P-NF- $\mathrm{KB} / \mathrm{NF}-\mathrm{KB}$ values of the LD and HD groups were decreased by $22.21 \%$ and $24.38 \%$, respectively (all $p<0.05)$. The values of iNOS $(12.59 \%$ and $28.54 \%)$ and COX-2 $(17.34 \%$ and $12.80 \%$, respectively) were decreased in the LD and HD groups (all $p<0.05$ ). SAVEP decreased the iNOS and COX-2 values compared with those in the model group. Therefore, high and low concentrations of SAVEP significantly inhibited the protein expression of the NF- $\mathrm{KB}$ pathway and downregulated the expression of iNOS and COX-2 proteins. 


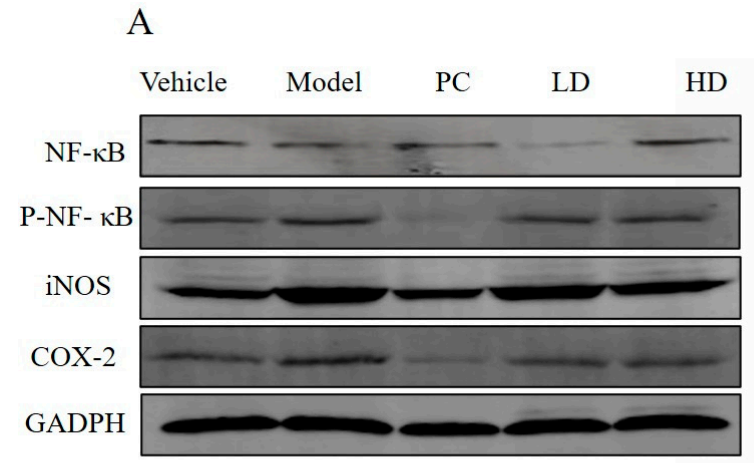

$\mathrm{C}$

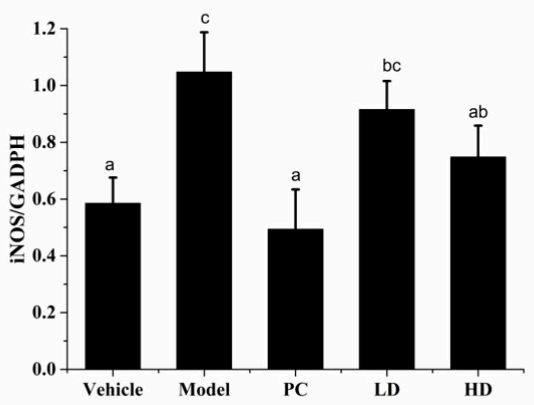

$\mathrm{B}$

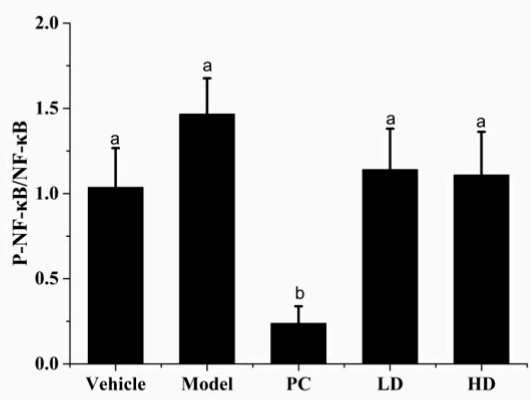

$\mathrm{D}$

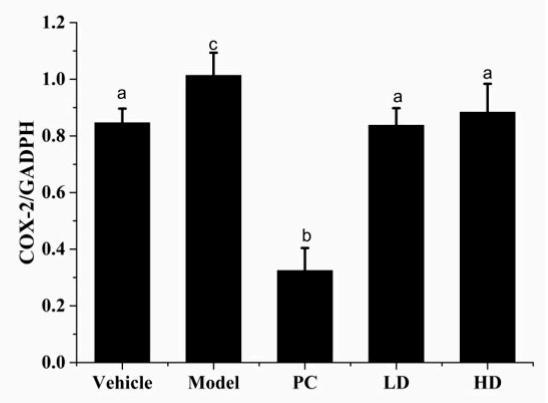

Figure 8. Effects of SAVEP on inflammatory protein expression in LPS-induced mice. (A) Expression levels of proteins were detected through Western blot analysis. (B) Quantitative analysis of P-NF- $\mathrm{BB}$ / NF- $\kappa B$ protein level. (C) Quantitative analysis of iNOS protein level. (D) Quantification of COX-2 protein expression. Statistical analysis was performed using a one-way ANOVA with Tukey's test. Data represent the mean $\pm \mathrm{SD}(n=6)$. Different letters represent significant differences between groups $(p<0.05)$.

\section{Discussion}

Shanxi-aged vinegar is a famous traditional solid fermentation vinegar in China [1] and consists of organic acids, sugars, proteins, amino acids, polyphenols, melanoidins, and other nutrients and flavour components, all of which have health-related and therapeutic properties [2]. Even though polyphenols are important antioxidant and anti-inflammatory compounds widely found in vinegar [22], the regulation mechanism of polyphenol extracts in vinegar in relation to inflammatory stress metabolism remains unknown. In this study, types of polyphenols were detected by GC-MS; then, the anti-inflammatory effects of SAVEP and their potential mechanisms were investigated in LPS-induced RAW 264.7 macrophages and inflammatory mice.

Cell damage was mainly manifested as changes in cell morphology, DNA damage, and mitochondrial membrane potential imbalance, which could lead to apoptosis [25-27]. Normal cell morphology shows roundness and fullness without cell membrane rupture and depression. However, when inflammatory cell damage occurs, the corresponding cell morphology changes as reflected in cell shrinkage, anisotropy, and depression [15]. SAVEP blocks the morphologic change in LPS-stimulated macrophages to a certain extent and plays a protective role in inflammatory-damaged macrophages. Our findings are basically consistent with those regarding the recovery effect of Rhododendron molle leaf extract (Main component are polyphenols) on LPS-induced RAW264.7 cell morphology [24]. A certain concentration of LPS can induce DNA damage and trigger inflammatory response, eventually leading to apoptosis. The shrinkage, lysis, and production of apoptotic bodies are important markers of cell apoptosis [26]. The shrinkage of macrophage nucleus caused by LPS occurs because the increase in ROS in cells induced by LPS leads to the dysfunction of cell mitochondria and consequently to the shrinkage of the nucleus [28]. Our results showed that SAVEP could effectively restore LPS-induced nuclear injury of macrophages. Moreover, this phenomenon was dose dependent, and the recovery effect of a high SAVEP 
concentration on macrophages was significantly higher than that of a low concentration. In regard to the research of procyanidin A2 for the treatment of LPS-induced inflammatory macrophages, procyanidin A2 effectively improved nuclear contraction [29]. These results suggested that polyphenols play an important role in protecting the nucleus.

Protecting mitochondria from free radicals is an important aspect of antioxidant and anti-inflammatory reactions [30]. Imbalance of mitochondrial membrane potential is regarded as an important marker of apoptosis [31]. Our finding indicates the downward trend of the LPS-induced mitochondrial membrane potential of macrophages. The groups treated with SAVEP showed significantly reduced intracellular green fluorescence intensity and enhanced intracellular red fluorescence intensity. It is suggested that the mitochondrial membrane potential of macrophages was enhanced. The change in the HD group was more evident than that in the LD group, indicating that this influence is positively correlated with concentration. The destruction of mitochondrial transmembrane potential is often associated with apoptosis and is one of the earliest events during apoptosis [32]. Procyanidin A2 has a similar effect to that of SAVEP in restoring the mitochondrial membrane potential of macrophages [29]. LPS-induced macrophages were studied by flow cytometry to investigate the effect of SAVEP on apoptosis. Our results indicate that LPS induced irreversible damage to the macrophages and resulted in cell apoptosis, which may be related to nuclear damage and the imbalance of mitochondrial membrane potential. SAVEP can reduce the apoptosis rate of macrophages by $22.99 \%$ and $29.19 \%$. These results show that SAVEP can help reduce the apoptosis of inflammatory macrophages. This trend was also confirmed by Qiu's research on the polyphenol-rich extract from Pleurotus eryngii's anti-inflammatory results for macrophages [33].

Pervasive cytokines (such as IL-6, IL-10, and TNF- $\alpha$ ) play critical roles in activated macrophages [34]. Inflammation has a complex pathogenesis. Cells produce stress response after external stimulation, and the level of inflammatory factors increases. This increased value is a key factor to determine the inflammatory stress response of cells [15]. Some believe that the overexpression of inflammatory factors is an important cause of inflammation. Therefore, inhibiting a large number of pro-inflammatory cytokines is considered a potential therapeutic strategy to regulate inflammation-related diseases [35,36]. In our study, the values of TNF- $\alpha$, IL-6, IL-18, IL-1 $\beta, \mathrm{MCP}-1$, and NO in the model group were all higher than those in the vehicle group. With SAVEP treatment, all of the indexes except NO showed a significant downward trend. The change in NO was small but still showed a downward trend. Excessive amounts of NO were associated with some inflammatory diseases [37]. Reducing NO, TNF- $\alpha$, IL-6, and IL-1 $\beta$ overexpression helps reduce inflammation [15]. It has been reported that Acalypha Australis L. can alleviate the damage caused by inflammatory stress through reducing the expression of TNF- $\alpha$ and IL-1 $\beta$ in inflammatory macrophages [35]. Experiments were also conducted on mice to further investigate the anti-inflammatory effects of SAVEP and obtain additional results. The serum levels of IL-1 $\beta$, IL-6, NO, and TNF- $\alpha$ in mice were consistent with those in inflammatory macrophages. Other inflammatory markers, such as IL-10, IgA, IgG, COX-2, and IgM, showed similar trends [38,39].

LPS triggers inflammation by binding to and activating receptor complexes on cell membranes. The receptor of LPS is the Toll-like receptor (TLR), which uses IL-1 signalling molecules (MyD88, IRAK, IRAK2, TRAF6, NIK, etc.) to mediate the activation of nuclear factor- $\kappa B$ (NF- $k B)$ in cells induced by LPS [40]. In addition to NF- $\kappa B$ activation, TLR activates mitogen-activated protein kinases (MAPKs) [41]. NF- $\kappa B$ is one of the most important inducible transcription factors in mammals and plays a key role in their innate immune response and chronic inflammation [42]. This systemic inflammatory response induces the expression of proinflammatory mediators, namely, enzymes, cytokines, and chemokines [43]. LPS activates ERK1/2, JNK, and p38 MAPK, which ultimately control the activity of transcription factors regulating the expression of inflammation modulators, such as induced NO synthase (iNOS), cyclooxygenase-2 (COX-2), TNF- $\alpha$, IL-1 $\alpha$, IL-1 $\beta$, and IL-6 [44]. Inhibiting the activation of NF-KB and MAPK signalling pathways is an 
important treatment strategy for inflammatory diseases [15,45]. Many anti-inflammatory effects shown by polyphenols may be achieved by influencing the transcription network, regulating gene expression, changing the inflammatory cell cycle of recruitment, or homing to a certain extent, thereby eventually inhibiting the activation of NF- $\mathrm{KB}$ and MAPK signalling pathways [46].

The MAPK protein family, including JNK1/2, ERK1/2, and p38 MAPK, regulates the inflammatory response of cells to external factors. Studies have shown that polyphenols, such as kaempferol, chrysin, apigenin, and luteolin, have been shown to be active inhibitors of TNF- $\alpha$ stimulated airway epithelial cell ICAM-1 expression by inhibiting all three mitogen-activated protein kinases, ERK, JNK, and P38 [47]. Related proteins were examined to confirm the effect of SAVEP on MAPK (ERK1/2, JNK and P38) family protein expression of RAW264.7 cells. The evidence shows that the dietary polyphenol ferulaldehyde can inhibit LPS-induced phosphorylation of JNK, ERK1/2, and p38 MAPK proteins, reducing MAPK activation, inhibiting NF-kB activation, and effectively prolonging the lifespan of LPS-treated mice [48]. Our results show that SAVEP inhibits LPS-induced phosphorylation of ERK1/2, JNK, and P38 proteins. LPS-induced MAPK phosphorylation is involved in iNOS, COX-2 protein expression, and proinflammatory factor activation [47]. Therefore, the degree of inflammation is reduced under the action of SAVEP. Studies have shown that polyphenols inhibit the expression of COX-2 by inhibiting the expression of MAPKs. COX-2 is known as an inducible enzyme that produces, in most cases, large amounts of prostaglandins. The reduction of prostaglandins content reduces inflammation [21]. Recent studies have shown that in LPS-activated mouse macrophage RAW264, pro-delphinidin B-4 3'-O-gallate, and pro-delphinidin B2 3,3' di-O-gallate inhibit COX-2 mRNA and protein expression in a dose-dependent manner $[21,49,50]$. SAVEP inhibits the expression of iNOS protein, which is related to the production of $\mathrm{NO}, \mathrm{NO}$ is involved in the inflammatory process, and the reduction of NO content alleviates the inflammation. It has been shown that polyphenols inhibit NO release by inhibiting NOS enzyme expression and/or NOS activity [21]. In LPS-stimulated macrophages of J774 mice, hydroxytyrosol inhibits the expression of COX-2 and iNOS genes; these findings are consistent with our results.

Inhibition of NF- $\mathrm{kB}$ is generally recognised as an effective strategy for the treatment of inflammatory diseases [51]. The NF- $\mathrm{kB}$ pathway is an important and attractive therapeutic target for compounds that selectively interfere with NF- $\mathrm{KB}$ [21]. The NF- $\mathrm{kB}$ signalling pathway regulates inflammatory response. NF- $\mathrm{KB}$ is an eukaryotic transcription factor belonging to the family of NF- $\mathrm{KB} /$ Rel P50, which is a heterodimer and NF- $\mathrm{KB}$ P65 [52]. NF- $\mathrm{KB}$ expression and P-NF- $\mathrm{KB}$ maintain an appropriate dynamic equilibrium that prevents pathological inflammation from damaging the body, but this dynamic equilibrium also leads to pathological inflammatory damage and changes in inflammatory markers under pathological conditions [53]. These results suggest that high SAVEP concentrations significantly inhibit the abnormally high NF- $\mathrm{kB}$ expression and reduce inflammatory stress in the body. Polyphenols exert their anti-inflammatory activity by regulating NF- $\mathrm{kB}$ activation and participating in several steps of the activation process [21,54]. Studies have shown that epigallocatechin gallate (EGCG) markedly attenuated the myocardial injury after ischemia and reperfusion in rats, and this cardio-protection was associated with inhibition of NF- $\mathrm{kB}$ activation, which was consistent with our research [21]. COX-2 protein expression is not only related to MAPKS, but it is also closely related to NF-KB. SAVEP inhibited the activation of NF- $\mathrm{KB}$, thereby affecting the expression of COX-2. The reduction of prostaglandin content associated with COX-2 protein was an important reason for the reduction of inflammation. Studies have found that the NF- $\mathrm{kB}$ signalling pathway is related to the expression of the iNOS protein. Preventing the binding of NF- $\mathrm{kB}$ to the iNOS gene promoter can cause inactivation of the iNOS protein and inhibit the transcription of iNOS. The result is that NO production decreases and inflammation is restored [55]. Tyrosol, along with lycopene and quercetin, inhibited the expression of COX-2 and iNOS genes in RAW 264.7 macrophages stimulated by gliadin in association with the NF- $\mathrm{kB}$ pathway. This finding is consistent with our findings [21]. The treatment of BV2 microglial 
cells with blueberry polyphenols has been shown to effectively reduce lipopolysaccharide (LPS)-induced pro-inflammatory mediators, such as nitric oxide (NO), interleukin 6 (IL-6), tumour necrosis factor-alpha (TNF- $\alpha$ ), interleukin-1 beta (IL-1 $\beta$ ), inducible NO, synthase (iNOS), and cyclooxygenase 2 (COX2). The effect was achieved by inhibiting the activation of the NF- $\mathrm{KB}$ signalling pathway and mediating the decrease in iNOS and COX2 protein expressions [56]. The inflammatory response is closely related to the immune response. Supplementation of taxifolin (a natural antioxidant polyphenol) significantly inhibited the NF- $\mathrm{kB}$ signalling pathway and significantly increased the secretions of IL-10, secretory immunoglobulin A, superoxide dismutase, and immunoglobulins ( $\operatorname{IgA}, \operatorname{IgG}$, and $\operatorname{IgM}$ ) in DSS-induced colitis mice [57]. Polyphenols isolated from virgin coconut oil attenuated cadmium-induced inflammation in rats. Inflammatory markers IL-6, CRP, and NO were significantly decreased [58]. The same trend was found in our study with the intervention of SAVEP; the NF- $\mathrm{kB}$ signalling pathway was inhibited, and the protein expressions of COX-2 and iNOS were decreased. The essence of inflammatory mediators is the expression of inflammatory proteins [56]. With the decrease in inflammatory protein expression, the contents of inflammatory mediators such as IL- 6, CRP, NO, IL- $1 \beta$, TNF- $\alpha$, iNOS, and COX-2 decreased and IL-10, IgA, and IgG increased.

As a polyphenol extract from foods, SAVEP has shown good anti-inflammatory effects, which provides a new direction for the clinical treatment of inflammation. Although polyphenols have anti-inflammatory potential, they are commonly associated with low bioavailability and an extremely limited half-life, which leads to weak potency and poor pharmacokinetics [59]. We investigated the protective effect of SAVEP on LPS-induced RAW264.7 macrophages and ICR mice, using more cell lines and expanding the number of assays where necessary. Studies further exploring the pharmacodynamics and pharmacokinetics of SAVEP are warranted.

\section{Materials and Methods}

\subsection{Materials and Chemicals}

SAV samples with eight years of ageing time were obtained from Shanxi-aged vinegar Group Co. Ltd. (Shanxi, China). D101 macroporous adsorption resin was purchased from Shanghai McLean Biochemical Technology Co., Ltd. Methanol, ethyl acetate, normal hexane, and N-butyl alcohol (all AR grade) were obtained from Sigma-Aldrich (St. Louis, MO, USA). Bis(trimethylsilyl)trifluoroacetamide (BSTFA) $+1 \%$ trimethylchlorosilane (TMCS) and 2,4,5-trihydroxybenzoic acid (all chromatographic grade) were obtained from Sinopharm Chemical Reagent Co., Ltd. (Shanghai, China). Total antioxidant capacity assay kits with ABTS and FRAP were purchased from the Beyotime Institute of Biotechnology (Shanghai, China). DPPH was obtained from Sinopharm Chemical Reagent Co., Ltd. (Shanghai, China). 5,5',6,6'-tetrachloro-1,1',3,3'-tetraethylbenzimidazolyl-carbocyanine iodide (JC-1), cell counting kit-8 (CCK-8), annexin V/PI, alanine aminotransferase (ALT), aspartate aminotransferase (AST), monocyte chemoattractant protein-1 (MCP-1), nitric oxide synthase (NOS), nitric oxide (NO), C-reactive protein (CRP), immunoglobulin G (IgG), immunoglobulin A (IgA), immunoglobulin $M(\operatorname{IgM})$, interleukin-1 $\beta$ (IL-1 $\beta)$, interleukin 6 (IL6), interleukin 10 (IL10), interleukin 18 (IL18), tumour necrosis factor $\alpha$ (TNF- $\alpha$ ), and protein assay kits were obtained from Beijing Boxbio Science \& Technology Co., Ltd. (Beijing, China). The primary antibodies against rabbit cyclooxygenase-2 (COX-2), inducible nitric oxide synthase (iNOS), Jun NH 2-terminal kinase (JNK), phospho-JNK (P-JNK), glyceraldehyde-3-phosphate dehydrogenase (GAPDH), p38 mitogen-activated protein kinase (p38 MAPK), phospho-p38 MAPK(P-p38 MAPK), extracellular signal regulated kinase(ERK1/2), phospho-ERK1/2(P-ERK1/2), and secondary horseradish peroxidaselabelled goat antirabbit antibodies were purchased from Abcam (Cambridge, UK). The antibodies against rabbit nuclear factor $\mathrm{\kappa B}(\mathrm{NF}-\mathrm{kB}$ ) and phosphorylated-NF- $\mathrm{kB}$ (P-NF- $\mathrm{kB}$ ) were acquired from Cell Signaling Technology, Inc. (Beverly, MA, USA). Phosphate buffer saline (PBS), low melting agarose, sodium dodecyl sulphate, tris buffered saline tween (TBST), and lipopolysaccharides (LPS) were obtained from Beijing Solarbio Technology 
Co., Ltd. (Beijing, China). Dulbecco's modified Eagle's medium (DMEM) was obtained from Life Technologies (Grand Island, NY, USA). Other reagents were acquired from Sigma-Aldrich (Germany). Polyvinylidene fluoride (PVDF) membranes were obtained from Millipore (Schwallbach, Germany).

\subsection{Polyphenol Extraction}

Every $10 \mathrm{~mL}$ of SAV was filtered through an ultrafiltration membrane with a pore diameter of $10 \mathrm{kDa}$ to remove the macromolecular impurities, such as proteins and melanoidins. The filtrate was then adsorbed to a D101 macroporous adsorption resin. After sample loading, the resin was washed with 10 times the volume of the resin of distilled water to remove saccharide and polar compounds, and it was then eluted with 10 times the volume of the resin of methanol. The preliminarily purified polyphenol extraction was obtained by vacuum evaporation of the methanol eluent. Components evaporated to dry were dissolved with $50 \mathrm{~mL}$ distilled water and then extracted with $50 \mathrm{~mL}$ ethyl acetate, n-hexane, and n-butanol in turn. The organic solvents were dried to obtain the polyphenol extracts; then, parts of the samples were dissolved with $10 \mathrm{~mL}$ distilled water and labelled as polyphenol extraction- $\mathrm{A}$, polyphenol extraction-B, and polyphenol extraction- $\mathrm{C}$. The other part was used for subsequent analysis.

Referring to our previous research methods [2], the total antioxidant activities of polyphenol extractions- $\mathrm{A},-\mathrm{B}$ and $-\mathrm{C}$, which were redissolved with $10 \mathrm{~mL}$ distilled water, were compared by DPPH, ABTS, and FRAP methods. The group with the highest total antioxidant activity was chosen among the three groups, which was detected by GC-MS.

\subsection{Analysis of Phenols of SAVEP}

GC-MS has always been the preferred method for (unknown) material analysis due to its superior separation performance and high sensitivity. Mass spectral libraries are available to facilitate the identification of unknown substances and thus are suitable for the detection and analysis of polyphenols [60]. The polyphenols in the samples are non-volatile compounds, so chemical derivational steps are required to obtain volatile and thermally stable derivatives [22]. Based on our previous findings [22], we used 2,4,5-trihydroxybenzoic acid as an internal standard substance to perform relative quantitative detection of polyphenols in SAVEP. Before the experiment started, $0.003 \mathrm{~g} \mathrm{2,4,5-trihydroxybenzoic} \mathrm{acid} \mathrm{was}$ added to $10 \mathrm{~mL}$ of SAV according to the method in the Polyphenol Extraction Section, and then, the extraction of polyphenols was continued. In the final result, the ratio of the "peak area" of the internal standard to the polyphenol is the ratio of the concentration of the internal standard to the concentration of the polyphenol.

Derivative reaction conditions: The extract corresponding to $10 \mathrm{~mL}$ of vinegar was collected, and $1 \mathrm{~mL}$ of BSTFA $+1 \%$ TMCS was added. The reaction was conducted at $70{ }^{\circ} \mathrm{C}$ for $3 \mathrm{~h}$ in a water bath.

GC-MS detection conditions: The GC-MS system consisted of a gas chromatograph combined with a fast-scanning quadrupole mass spectrometer (GCMS QP2010, Shimadzu Corp, Kyoto, Japan) and an AOC-2000 autosampler. The injector temperature was $300{ }^{\circ} \mathrm{C}$. Helium was used as carrier gas. The column was an HP-5 capillary column $(30 \mathrm{~m} \times$ $250 \mu \mathrm{m}$ i.d. $\times 0.25 \mu \mathrm{m}$ film thickness, Agilent Technologies, Cheadle, Cheshire, UK). The GC temperature ranging from $100^{\circ} \mathrm{C}$ to $280^{\circ} \mathrm{C}$ at $3{ }^{\circ} \mathrm{C} / \mathrm{min}$ resulted in a total run time of $60 \mathrm{~min}$. The transfer line was held at $300^{\circ} \mathrm{C}$. MS was operated at a maximum scan speed of $20,000 \mathrm{amu} / \mathrm{s}$ and at a scan range of 50-700 m/z, corresponding to a data acquisition rate of $33.3 \mathrm{~s}^{-1}$ (event time: $0.03 \mathrm{~s}$ ). An ion source temperature of $200{ }^{\circ} \mathrm{C}$ was selected, and $70 \mathrm{eV}$ EI spectra were recorded [22]. The National Institute Standard and Technology (NIST) was used to explain the GC-MS. The spectrum of unknown components was compared with the spectrum of the NIST (2011 version) library [61]. 


\subsection{Cell Culture and Cell Viability Assay}

RAW 264.7 macrophages were acquired from Wuhan Cell Bank, Chinese Academy of Sciences (Hubei, China) and cultured in DMEM medium containing $10 \%$ foetal bovine serum at $37{ }^{\circ} \mathrm{C}$ in a $5 \% \mathrm{CO}_{2}$ incubator for $24 \mathrm{~h}$. The cells were inoculated and treated with SAVEP of different concentrations for $24 \mathrm{~h}$ and then added with $1 \mu \mathrm{g} / \mathrm{mL}$ LPS for $12 \mathrm{~h}$. The four groups were the vehicle group (vehicle, without LPS and SAVEP), model group (model, $1 \mu \mathrm{g} / \mathrm{mL}$ LPS), SAVEP high-dose group (HD, $1 \mu \mathrm{g} / \mathrm{mL}$ LPS and $400 \mu \mathrm{g} / \mathrm{mL}$ SAVEP), and SAVEP low-dose group (LD, $1 \mu \mathrm{g} / \mathrm{mL}$ LPS and $200 \mu \mathrm{g} / \mathrm{mL}$ SAVEP). Cell viability was determined by CCK- 8 assay. RAW 264.7 macrophages $\left(6 \times 10^{4}\right.$ cells/well $)$ were inoculated in 96-well plates and incubated overnight prior to experimental intervention. The cells were then treated with samples of different concentrations for $24 \mathrm{~h}$, added with $10 \mu \mathrm{L}$ of CCK-8 in each coating, and incubated at $37{ }^{\circ} \mathrm{C} 5 \% \mathrm{CO}_{2}$ for $2 \mathrm{~h}$ [62]. Optical density was then read at $450 \mathrm{~nm}$ using a microplate reader (Thermo Fisher Scientific, Multiskan Sky, Waltham, MA, USA). Absorbance was compared between the sample and vehicle group.

\subsection{Scanning Electron Microscopy (SEM)}

RAW264.7 macrophages $\left(1 \times 10^{5}\right.$ cells/well $)$ were cultured into six-well plates per hole at $37{ }^{\circ} \mathrm{C}$ and $5 \% \mathrm{CO}_{2}$ for $24 \mathrm{~h}$. Pre-cooled PBS buffer was added to the hole containing the glass sheet for cleaning twice. Afterwards, $2.5 \%$ glutaraldehyde fixative was added to the hole and placed in the refrigerator at $4{ }^{\circ} \mathrm{C}$ for $3 \mathrm{~h}$. The samples were washed again with PBS buffer. The water in the sample was removed through gradient dehydration with ethanol. The concentration of dehydrating agent was 30\%, 50\%, $70 \%, 80 \%, 90 \%$, and $100 \%$ (once), and the dehydration time was 15 min per step. The samples were dried in a critical point dryer for $2 \mathrm{~h}$. SEM was conducted at $10 \mathrm{kV}$. The samples were sprinkled onto conductive glue on an aluminium SEM stub and sputter coated with gold.

\subsection{Hoechst 33342/Propidium Iodide (PI) Staining}

RAW264.7 macrophages $\left(1 \times 10^{5}\right.$ cells / well $)$ were cultured into a six-well plate per hole at $37^{\circ} \mathrm{C}$ and $5 \% \mathrm{CO}_{2}$. After $6 \mathrm{~h}$, the cells were washed with PBS buffer three times. After the final wash, DMEM cell culture medium was added. The cells were then stimulated by LPS for $24 \mathrm{~h}$, and some were added with SAVEP. Briefly, $1 \mu \mathrm{L}$ of Hoechst 33,342 dye $(1 \mathrm{mg} / \mathrm{mL})$ was added to each well. The cells were incubated in darkness at $37^{\circ} \mathrm{C}$ for $10 \mathrm{~min}$ and then washed twice with pre-cooled PBS buffer [62,63]. Red and green fluorescence spots were observed by a fluorescence microscopy (Thermo Fisher Scientific, EVOS M5000, Waltham, Massachusetts, USA) equipped with a DXM1200C colour digital camera (Nikon Corporation, Kumagaya, Saitama, Japan) and processed using NIS-Elements Basic Research v2.2 software.

\subsection{JC-1 Staining}

RAW 264.7 macrophages $\left(1 \times 10^{5}\right.$ cells/well $)$ were cultured into a six-well plate per hole at $37^{\circ} \mathrm{C}$ and $5 \% \mathrm{CO}_{2}$. After $6 \mathrm{~h}$, the cells were washed with PBS buffer three times. After the final wash, DMEM cell culture medium was added. The cells were then stimulated by LPS for $24 \mathrm{~h}$, and some were added with SAVEP. Concentrated JC- 1 solution was diluted into a $5 \mathrm{~g} / \mathrm{mL}$ working solution using DMEM medium. After mixing, the concentrated solution was added to the pore plate containing cells. The solution was placed in an incubator and incubated in darkness for $20 \mathrm{~min}$ [64]. Red and green fluorescence spots were observed by fluorescence microscopy (Thermo Fisher Scientific, EVOS M5000, Waltham, MA, USA).

\subsection{Annexin V-FITC/PI Staining}

RAW264.7 macrophages $\left(1 \times 10^{5}\right.$ cells / well $)$ were cultured into a six-well plate per hole at $37^{\circ} \mathrm{C}$ and $5 \% \mathrm{CO}_{2}$. After $6 \mathrm{~h}$, the cells were washed with PBS buffer three times, collected, centrifuged at $4000 \mathrm{r} / \mathrm{min}$ for $5 \mathrm{~min}$, and resuspended with cold PBS buffer. 
The samples were tested by flow cytometry (Thermo Fisher Scientific, Attune NxT, Waltham, MA, USA). FlowJo Collectors Edition (Tree Star, Ashland, OR, USA) was used as acquisition software. The samples were diluted with $1 \times$ PBS to produce solutions in which events were detected at a maximum rate of $1000 \mathrm{MPs}$ per second. The dilutions ranged from 1:5 to 1:50 depending on the sample concentration. With predetermined parameters, events that exceed the minimum size threshold were collected. Data were collected until 10,000 events had been counted or $1 \mathrm{~min}$ had elapsed after the count, subtracting background events for buffering only, and the counts/ $\mu \mathrm{L}$ sample was calculated using the recorded flow rate of the machine.

Samples were stained separately with annexin V/PI binding solution $(195 \mu \mathrm{L})$, annexin $\mathrm{V}$ dye $(10 \mu \mathrm{L})$, and propidium iodide $(5 \mu \mathrm{L} \mathrm{PI})$, and they were incubated in dark for $20 \mathrm{~min}$. A total of $500 \mu \mathrm{L}$ was prepared for each sample [65]. The data were analysed using FlowJo analysis software.

\subsection{Analysis of Cytokine Expression and Mouse Serum Index}

RAW 264.7 macrophages were pre-treated with LPS $(1 \mu \mathrm{g} / \mathrm{mL})$ in six-well plates for $24 \mathrm{~h}$ and cultured with different samples for another $24 \mathrm{~h}$. TNF- $\alpha$, IL-1 $\beta$, IL-6, IL-18, MCP-1, and NO levels in the supernatants were measured by using commercial kits in accordance with the manufacturer's standards and protocols [63].

Mouse serum supernatants were collected through centrifugation at $5000 \mathrm{r} / \mathrm{min}$ for $15 \mathrm{~min}$. Relevant indicators were analysed with commercial kits in accordance with the manufacturer's standards and protocols [22].

\subsection{Western Blot Analysis}

Methods of protein extraction and incubation from RAW264.7 macrophages and mouse liver tissue were performed as described $[62,63,66]$. In brief, RAW264.7 macrophages or the liver tissues of mice were lysed and centrifuged at 12,000 rpm for $30 \mathrm{~min}$ to remove the fragments and impurities. The proteins were resolved by $12 \%$ SDS-polyacrylamide jell electrophoresis. Proteins were transferred to PVDF membranes and incubated for $2 \mathrm{~h}$ with skim milk in TBST. Blots were probed using the following primary antibodies: anti-p38 antibody (1:1000), anti-P-p38 antibody (1:1000), anti-ERK1/2 antibody (1:1000), anti-PERK1/2 antibody (1:1000), anti-NF-KB antibody (1:1000), anti-P-NF-KB antibody (1:1000), anti-iNOS antibody (1:1000), anti-COX-2 antibody (1:1000), anti-P-JNK antibody (1:1000), anti-JNK antibody (1:1000), and anti-GADPH antibody (1:1000). After the specimens were incubated with the primary antibody, the secondary antibodies were added. Western blot bands were quantified using Image J.

\subsection{Animals, Fodder and Treatment}

All experiments involving mice were conducted in accordance with the protocol approved by the animal protection and use committee of Tianjin University of Science \& Technology. Male ICR mice (18-22 g) were purchased from the China National Institute for Food and Drug Control (License No.: SCXK (Beijing) 2016-002) and raised in the animal experiment centre (SPF) of the College of Biological Engineering, Tianjin University of Science and Technology. The indoor ventilation conditions were good, the relative humidity was controlled at $55 \% \pm 5 \%$, and the temperature was $23 \pm 2{ }^{\circ} \mathrm{C}$. Conventional diet and free intake of food and water were administered for 1 week for the subjects to adapt to the environment. A regular $12 \mathrm{~h}$ day $/ 12 \mathrm{~h}$ night cycle was adopted [22].

The conventional feed components contained $59 \%$ carbohydrates, $21.1 \%$ proteins, $4.9 \%$ fibres, $4.2 \%$ fat, $8 \%$ ash, $1 \%$ phosphorus, and $1.8 \%$ calcium. The conventional feed was purchased from Beijing Keao Xieli Feed Co., Ltd.

The mice were randomly divided into five groups $(n=6)$, namely, vehicle, model (LPSinduced), PC (positive control, LPS-induced, and $5 \mathrm{mg} / \mathrm{kg}$ dexamethasone) and test groups (LD/HD), which received different doses of SAVEP (LPS-induced and 0.625/1.250 mL/ $\mathrm{kg}$ SAVEP). All groups were intraperitoneally injected with $1.5 \mathrm{mg} \cdot \mathrm{kg}^{-1} \mathrm{LPS}$ in the first day, 
except for the vehicle group that was intraperitoneally injected with the same amount of normal saline. The experimental group was intraperitoneally gavaged with different doses of SAVEP for 7 days after continuous intervention, and the model and experimental groups were intraperitoneally injected with $1.5 \mathrm{mg} \cdot \mathrm{kg}^{-1}$ LPS again $1 \mathrm{~h}$ after intervention on day 7. After $30 \mathrm{~min}$, the mice were euthanised by an overdose of anaesthesia, and blood was collected. Finally, the liver was collected and placed in a $-80^{\circ} \mathrm{C}$ environment.

All animal procedures were performed in accordance with the Guidelines for Care and Use of Laboratory Animals (Ministry of Science and Technology of China, 2006) and were supported by the Institutional Animal Committee of Tianjin University of Science \& Technology (TUST20180522).

\subsection{Statistical Analysis}

Each sampling dataset was repeated at least three times. Statistical analysis was performed using a one-way ANOVA with Tukey's test. Origin 9.1 was used to draw the figures, and experimental data are expressed as mean \pm SD with $p<0.05$ as the standard for significant difference.

\section{Conclusions}

In summary, we detected 19 types of polyphenols in SAVEP. SAVEP can significantly improve LPS-induced inflammation, restore cell morphology, repair damaged nuclei, and recover the abnormal mitochondrial membrane potential, thus reducing cell apoptosis. SAVEP can inhibit the activation of the MAPK pathway in RAW264.7 and the NF- $\mathrm{kB}$ pathway in mice, inhibiting the expression of iNOS and COX-2 proteins and consequently the production of inflammatory factors, thus alleviating inflammatory stress. This compound can normalise the expression of related proteins and consequently the production of inflammatory factors, thus alleviating inflammatory stress. Therefore, our results suggest that SAVEP may be a novel strategy against inflammation.

Supplementary Materials: The following are available online, Figure S1: Evaluation of antioxidant activity of polyphenol extracts. (A) DPPH method. (B) ABTS method. (C) FRAP method. Data represent the mean $\pm \mathrm{SD}(n=6)$. Values in the same row with different letters are significantly different $(p<0.05)$. Figure S2: Effects of SAVEP on RAW264.7 cell morphology of LPS-induced inflammatory injury with SEM $(9500 \times)$. (A) Vehicle group. (B) Model group. (C) LD group. (D) HD group. Table S1: Results of polyphenol detected by GC-MS in SAVEP.

Author Contributions: Conceptualisation and methodology: P.D. and J.S.; validation: P.D. and H.Q.; data analysis: H.L. and L.Z.; investigation: J.Z. and S.J;; writing—original draft preparation: P.D., J.L. and J.S.; writing—review and editing: P.D., Y.Z. and M.W.; funding acquisition: M.W. and J.S. All authors have read and agreed to the published version of the manuscript.

Funding: This research was funded by the National Key R\&D Program of China (2016YFD0400505), the Natural Science Foundation of China (81600126, 32072203), the Tianjin Municipal Education Commission (TD13-5013), the Foundation of Key Laboratory of Industrial Fermentation Microbiology of Ministry of Education and Tianjin Key Lab of Industrial Microbiology (Tianjin University of Science \& Technology) (2020KF004) and the Key Research and Development Program of Zibo City(2020kj050008).

Institutional Review Board Statement: All animal procedures were performed in accordance with the Guidelines for Care and Use of Laboratory Animals (Ministry of Science and Technology of China, 2006) and were supported by the Institutional Animal Committee of Tianjin University of Science \& Technology (TUST20180522).

Informed Consent Statement: Not applicable.

Data Availability Statement: All generated and analysed data used to support the findings of this study are included within the article.

Acknowledgments: Thanks to the products and services provided by Beijing Boxbio Science \& Technology Co., Ltd. 
Conflicts of Interest: The authors declare no conflict of interest.

Sample Availability: Samples of the Shanxi-aged vinegar are available from the authors.

\section{References}

1. Chen, H.; Chen, T.; Giudici, P.; Chen, F. Vinegar Functions on Health: Constituents, Sources, and Formation Mechanisms. Compr. Rev. Food Sci. Food Saf. 2016, 15, 1124-1138. [CrossRef] [PubMed]

2. Zhao, C.; Xia, T.; Du, P.; Duan, W.; Zhang, B.; Zhang, J.; Zhu, S.; Zheng, Y.; Wang, M.; Yu, Y. Chemical Composition and Antioxidant Characteristic of Traditional and Industrial Zhenjiang Aromatic Vinegars during the Aging Process. Molecules 2018, 23, 2949. [CrossRef] [PubMed]

3. Ren, M.M.; Wang, X.Y.; Tian, C.R.; Li, X.J.; Zhang, B.S.; Song, X.Z.; Zhang, J. Characterization of Organic Acids and Phenolic Compounds of Cereal Vinegars and Fruit Vinegars in China. J. Food Process. Preserv. 2017, 41. [CrossRef]

4. Samad, A.; Azlan, A.; Ismail, A. Therapeutic effects of vinegar: A review. Curr. Opin. Food Sci. 2016, 8, 56-61. [CrossRef]

5. Banach, M.; Wiloch, M.; Zawada, K.; Cyplik, W.; Kujawski, W. Evaluation of Antioxidant and Anti-Inflammatory Activity of Anthocyanin-Rich Water-Soluble Aronia Dry Extracts. Molecules 2020, 25, 4055. [CrossRef]

6. Date, A.A.; Destache, C.J. Natural polyphenols: Potential in the prevention of sexually transmitted viral infections. Drug Discov. Today 2016, 21, 333-341. [CrossRef] [PubMed]

7. Costa, C.; Tsatsakis, A.; Mamoulakis, C.; Teodoro, M.; Briguglio, G.; Caruso, E.; Tsoukalas, D.; Margina, D.; Dardiotis, E.; Kouretas, D.; et al. Current evidence on the effect of dietary polyphenols intake on chronic diseases. Food Chem. Toxicol. 2017, 110, 286-299. [CrossRef] [PubMed]

8. Giglio, R.V.; Patti, A.M.; Cicero, A.F.G.; Lippi, G.; Rizzo, M.; Toth, P.P.; Banach, M. Polyphenols: Potential Use in the Prevention and Treatment of Cardiovascular Diseases. Curr. Pharm. Des. 2018, 24, 239-258. [CrossRef] [PubMed]

9. Reuter, S.; Gupta, S.C.; Chaturvedi, M.M.; Aggarwal, B.B. Oxidative stress, inflammation, and cancer: How are they linked? Free Radic. Biol. Med. 2010, 49, 1603-1616. [CrossRef] [PubMed]

10. Vauzour, D.; Rodriguez-Mateos, A.; Corona, G.; Oruna-Concha, M.J.; Spencer, J.P. Polyphenols and human health: Prevention of disease and mechanisms of action. Nutrients 2010, 2, 1106-1131. [CrossRef] [PubMed]

11. Han, J.M.; Lee, E.K.; Gong, S.Y.; Sohng, J.K.; Kang, Y.J.; Jung, H.J. Sparassis crispa exerts anti-inflammatory activity via suppression of TLR-mediated NF- $\mathrm{B}$ and MAPK signaling pathways in LPS-induced RAW264.7 macrophage cells. J. Ethnopharmacol. 2019, 231, 10-18. [CrossRef]

12. Li, C.-L.; Tan, L.-H.; Wang, Y.-F.; Luo, C.-D.; Chen, H.-B.; Lu, Q.; Li, Y.-C.; Yang, X.-B.; Chen, J.-N.; Liu, Y.-H.; et al. Comparison of anti-inflammatory effects of berberine, and its natural oxidative and reduced derivatives from Rhizoma Coptidis in vitro and in vivo. Phytomedicine 2019, 52, 272-283. [CrossRef] [PubMed]

13. Shimegi, S.; Fischer, Q.S.; Yang, Y.; Sato, H.; Daw, N.W. Blockade of Cyclic AMP-Dependent Protein Kinase Does Not Prevent the Reverse Ocular Dominance Shift in Kitten Visual Cortex. J. Neurophysiol. 2003, 90, 4027-4032. [CrossRef] [PubMed]

14. Aulakh, R.; Singh, S. Strategies for minimizing corticosteroid toxicity: A review. Indian J. Pediatr 2008, 75, 1067-1073. [CrossRef] [PubMed]

15. Mun, S.-K.; Kang, K.-Y.; Jang, H.-Y.; Hwang, Y.-H.; Hong, S.-G.; Kim, S.-J.; Cho, H.-W.; Chang, D.-J.; Hur, J.-S.; Yee, S.-T. Atraric Acid Exhibits Anti-Inflammatory Effect in Lipopolysaccharide-Stimulated RAW264.7 Cells and Mouse Models. Int. J. Mol. Sci. 2020, 21, 7070. [CrossRef] [PubMed]

16. Miles, E.A.; Zoubouli, P.; Calder, P.C. Effects of polyphenols on human Th1 and Th2 cytokine production. Clin. Nutr. 2005, 24, 780-784. [CrossRef]

17. Biesalski, H.K. Polyphenols and inflammation: Basic interactions. Curr. Opin. Clin. Nutr. Metab. Care 2007, 10, 724-728. [CrossRef] [PubMed]

18. Konukoglu, D.; Turhan, M.S.; Ercan, M.; Serin, O. Relationship between plasma leptin and zinc levels and the effect of insulin and oxidative stress on leptin levels in obese diabetic patients. J. Nutr. Biochem. 2004, 15, 757-760. [CrossRef] [PubMed]

19. Kundu, J.K.; Na, H.K.; Chun, K.S.; Kim, Y.K.; Lee, S.J.; Lee, S.S.; Lee, O.S.; Sim, Y.C.; Surh, Y.J. Inhibition of phorbol ester-induced COX-2 expression by epigallocatechin gallate in mouse skin and cultured human mammary epithelial cells. J. Nutr. 2003, 133, 3805S-3810S. [CrossRef] [PubMed]

20. Doster, M.A.; Michailides, T.J. Production of Bright Greenish Yellow Fluorescence in Figs Infected by Aspergillus Species in California Orchards. Plant Dis. 1998, 82, 669-673. [CrossRef] [PubMed]

21. Santangelo, C.; Varì, R.; Scazzocchio, B.; Di Benedetto, R.; Filesi, C.; Masella, R. Polyphenols, intracellular signalling and inflammation. Annali dell'Istituto Superiore di Sanità 2007, 43, 394-405.

22. Du, P.; Zhou, J.; Zhang, L.; Zhang, J.; Li, N.; Zhao, C.; Tu, L.; Zheng, Y.; Xia, T.; Luo, J.; et al. GC x GC-MS analysis and hypolipidemic effects of polyphenol extracts from Shanxi-aged vinegar in rats under a high fat diet. Food Funct. 2020, 11, 7468-7480. [CrossRef]

23. Rabah, S.; Kouachi, K.; Ramos, P.A.B.; Gomes, A.P.; Almeida, A.; Haddadi-Guemghar, H.; Madani, K.; Silvestre, A.J.D.; Santos, S.A.O. Unveiling the bioactivity of Allium triquetrum L. lipophilic fractions: Chemical characterization and in vitro antibacterial activity against methicillin-resistant Staphylococcus aureus. Food Funct. 2020, 11, 5257-5265. [CrossRef]

24. Zong, L.; Zhang, J.; Dai, L.; Liu, J.; Yang, Y.; Xie, J.; Luo, X. The Anti-Inflammatory Properties of Rhododendron molle Leaf Extract in LPS-Induced RAW264.7. Chem. Biodivers. 2020. [CrossRef] 
25. Zamzami, N.; Hirsch, T.; Dallaporta, B.; Petit, P.X.; Kroemer, G. Mitochondrial implication in accidental and programmed cell death: Apoptosis and necrosis. J. Bioenerg. Biomembr. 1997, 29, 185-193. [CrossRef]

26. Ferri, K.F.; Kroemer, G. Organelle-specific initiation of cell death pathways. Nat. Cell Biol. 2001, 11, E255-E263. [CrossRef]

27. Kim, R.; Emi, M.; Tanabe, K. Role of mitochondria as the gardens of cell death. Cancer Chemother. Pharm. 2006, 57, 545-553. [CrossRef]

28. Ayala, A.; Munoz, M.F.; Arguelles, S. Lipid peroxidation: Production, metabolism, and signaling mechanisms of malondialdehyde and 4-hydroxy-2-nonenal. Oxid. Med. Cell. Longev. 2014, 2014, 360438. [CrossRef] [PubMed]

29. Wang, Q.Q.; Gao, H.; Yuan, R.; Han, S.; Li, X.X.; Tang, M.; Dong, B.; Li, J.X.; Zhao, L.C.; Feng, J.; et al. Procyanidin A2, a polyphenolic compound, exerts anti-inflammatory and anti-oxidative activity in lipopolysaccharide-stimulated RAW264.7 cells PLoS ONE 2020, 15, e0237017. [CrossRef] [PubMed]

30. Ci, X.; Zhou, J.; Lv, H.; Yu, Q.; Peng, L.; Hua, S. Betulin exhibits anti-inflammatory activity in LPS-stimulated macrophages and endotoxin-shocked mice through an AMPK/AKT/Nrf2-dependent mechanism. Cell Death Dis. 2017, 8, e2798. [CrossRef]

31. Perelman, A.; Wachtel, C.; Cohen, M.; Haupt, S.; Shapiro, H.; Tzur, A. JC-1: Alternative excitation wavelengths facilitate mitochondrial membrane potential cytometry. Cell Death Dis. 2012, 3, e430. [CrossRef]

32. Lizard, G.; Miguet, C.; Besséde, G.; Monier, S.; Gueldry, S.; Neel, D.; Gambert, P. Impairment with various antioxidants of the loss of mitochondrial transmembrane potential and of the cytosolic release of cytochrome c occuring during 7-ketocholesterol-induced apoptosis. Free Radic. Biol. Med. 2000, 28, 743-753. [CrossRef]

33. Hu, Q.; Yuan, B.; Xiao, H.; Zhao, L.; Wu, X.; Rakariyatham, K.; Zhong, L.; Han, Y.; Kimatu, M.B.; Yang, W. Polyphenols-rich extract from Pleurotus eryngii with growth inhibitory of HCT116 colon cancer cells and anti-inflammatory function in RAW264.7 cells. Food Funct. 2018, 9, 1601-1611. [CrossRef]

34. Lee, S.B.; Lee, W.S.; Shin, J.S.; Jang, D.S.; Lee, K.T. Xanthotoxin suppresses LPS-induced expression of iNOS, COX-2, TNF- $\alpha$, and IL-6 via AP-1, NF-kB, and JAK-STAT inactivation in RAW 264.7 macrophages. Int. Immunopharmacol. 2017, 49, 21-29. [CrossRef]

35. Kim, H.-J.; Joe, H.-I.; Zhang, Z.; Lee, W.S.; Lee, K.-Y.; Kook, Y.-B.; An, H.-J. Anti-inflammatory effect of Acalypha australis L. via suppression of NF-kB signaling in LPS-stimulated RAW 264.7 macrophages and LPS-induced septic mice. Mol. Immunol. 2020, 119, 123-131. [CrossRef]

36. Cho, E.J.; An, H.J.; Shin, J.S.; Choi, H.E.; Ko, J.; Cho, Y.W.; Kim, H.M.; Choi, J.H.; Lee, K.T. Roxatidine suppresses inflammatory responses via inhibition of NF- $\mathrm{kB}$ and p38 MAPK activation in LPS-induced RAW 264.7 macrophages. J. Cell. Biochem. 2011, 112, 3648-3659. [CrossRef]

37. Liu, T.; Xiao, N.; Liu, Y.; Wilson, B.; Li, J.; Wang, Y.; Cao, X.; Liu, Z. The anti-inflammatory effects of ethyl acetate on Lipopolysaccharide/D-galactosamine challenged mice and Lipopolysaccharide activated RAW264.7 cells. Biochem. Biophys. Res. Commun. 2012, 427, 518-524. [CrossRef]

38. Tang, C.; Sun, J.; Liu, J.; Jin, C.; Wu, X.; Zhang, X.; Chen, H.; Gou, Y.; Kan, J.; Qian, C.; et al. Immune-enhancing effects of polysaccharides from purple sweet potato. Int. J. Biol. Macromol. 2019, 123, 923-930. [CrossRef] [PubMed]

39. Heeg, A.; Kuchler, L.; Eifler, L.K.; Knape, T.; Heide, H.; Brüne, B.; von Knethen, A. LPS-induced Pellino3 degradation is mediated by p62-dependent autophagy. Crit. Care 2012, 16, P50. [CrossRef]

40. Oda, K.; Kitano, H. A comprehensive map of the toll-like receptor signaling network. Mol. Syst. Biol. 2006, 2, 2006.0015. [CrossRef]

41. An, H.; Xu, H.; Yu, Y.; Zhang, M.; Qi, R.; Yan, X.; Liu, S.; Wang, W.; Guo, Z.; Qin, Z.; et al. Up-regulation of TLR9 gene expression by LPS in mouse macrophages via activation of NF-kB, ERK and p38 MAPK signal pathways. Immunol. Lett. 2002, 81, 165-169. [CrossRef]

42. Guimaraes, M.R.; Leite, F.R.; Spolidorio, L.C.; Kirkwood, K.L.; Rossa, C., Jr. Curcumin abrogates LPS-induced pro-inflammatory cytokines in RAW 264.7 macrophages. Evidence for novel mechanisms involving SOCS-1, -3 and p38 MAPK. Arch. Oral. Biol. 2013, 58, 1309-1317. [CrossRef]

43. Neuder, L.E.; Keener, J.M.; Eckert, R.E.; Trujillo, J.C.; Jones, S.L. Role of p38 MAPK in LPS induced pro-inflammatory cytokine and chemokine gene expression in equine leukocytes. Vet. Immunol. Immunopathol. 2009, 129, 192-199. [CrossRef]

44. Somensi, N.; Rabelo, T.K.; Guimaraes, A.G.; Quintans-Junior, L.J.; de Souza Araujo, A.A.; Moreira, J.C.F.; Gelain, D.P. Carvacrol suppresses LPS-induced pro-inflammatory activation in RAW 264.7 macrophages through ERK1/2 and NF-kB pathway. Int. Immunopharmacol. 2019, 75, 105743. [CrossRef] [PubMed]

45. Yang, M.; Wang, Y.; Patel, G.; Xue, Q.; Singor Njateng, G.S.; Cai, S.; Cheng, G.; Kai, G. In vitro and in vivo anti-inflammatory effects of different extracts from Epigynum auritum through down-regulation of NF- $\mathrm{BB}$ and MAPK signaling pathways. J. Ethnopharmacol. 2020, 261, 113105. [CrossRef]

46. Tangney, C.C.; Rasmussen, H.E. Polyphenols, inflammation, and cardiovascular disease. Curr. Atheroscler. Rep. $2013,15,324$. [CrossRef]

47. Im, J.Y.; Kim, D.; Lee, K.W.; Kim, J.B.; Lee, J.K.; Kim, D.S.; Lee, Y.I.; Ha, K.S.; Joe, C.O.; Han, P.L. COX-2 Regulates the InsulinLike Growth Factor I-Induced Potentiation of $\mathrm{Zn}(2+)$-Toxicity in Primary Cortical Culture. Mol. Pharmacol. 2004, 66, 368-376. [CrossRef] [PubMed]

48. Tucsek, Z.; Radnai, B.; Racz, B.; Debreceni, B.; Priber, J.K.; Dolowschiak, T.; Palkovics, T.; Gallyas, F., Jr.; Sumegi, B.; Veres, B. Suppressing LPS-induced early signal transduction in macrophages by a polyphenol degradation product: A critical role of MKP-1. J. Leukoc. Biol. 2011, 89, 105-111. [CrossRef] [PubMed] 
49. Hou, D.X.; Luo, D.; Tanigawa, S.; Hashimoto, F.; Uto, T.; Masuzaki, S.; Fujii, M.; Sakata, Y. Prodelphinidin B-4 3'-O-gallate, a tea polyphenol, is involved in the inhibition of COX-2 and iNOS via the downregulation of TAK1-NF-KB pathway. Biochem. Pharmacol. 2007, 74, 742-751. [CrossRef]

50. Hou, D.X.; Masuzaki, S.; Hashimoto, F.; Uto, T.; Tanigawa, S.; Fujii, M.; Sakata, Y. Green tea proanthocyanidins inhibit cyclooxygenase-2 expression in LPS-activated mouse macrophages: Molecular mechanisms and structure-activity relationship. Arch. Biochem. Biophys. 2007, 460, 67-74. [CrossRef]

51. Karin, M.; Yamamoto, Y.; Wang, Q.M. The IKK NF-kB system: A treasure trove for drug development. Nat. Rev. Drug Discov. 2004, 3, 17-26. [CrossRef]

52. Lee, T.H.; Tai, D.I.; Cheng, C.J.; Sun, C.S.; Lin, C.Y.; Sheu, M.J.; Lee, W.P.; Peng, C.Y.; Wang, A.H.; Tsai, S.L. Enhanced nuclear factor-kappa B-associated Wnt-1 expression in hepatitis B- and C-related hepatocarcinogenesis: Identification by functional proteomics. J. Biomed. Sci. 2006, 13, 27-39. [CrossRef]

53. Sun, X.; Yuan, X.; Chen, L.; Wang, T.; Wang, Z.; Sun, G.; Li, X.; Li, X.; Liu, G. Histamine Induces Bovine Rumen Epithelial Cell Inflammatory Response via NF-кB Pathway. Cell. Physiol. Biochem. 2017, 42, 1109-1119. [CrossRef] [PubMed]

54. Rahman, I.; Biswas, S.K.; Kirkham, P.A. Regulation of inflammation and redox signaling by dietary polyphenols. Biochem. Pharmacol. 2006, 72, 1439-1452. [CrossRef]

55. Lin, Y.-L.; Lin, J.-K. (-)-Epigallocatechin-3-gallate Blocks the Induction of Nitric Oxide Synthase by Down-Regulating Lipopolysaccharide-Induced Activity of Transcription Factor Nuclear Factor-kB. Mol. Pharmacol. 1997, 52, 465-472. [CrossRef]

56. Lau, F.C.; Joseph, J.A.; McDonald, J.E.; Kalt, W. Attenuation of iNOS and COX2 by blueberry polyphenols is mediated through the suppression of NF-kB activation. J. Funct. Foods 2009, 1, 274-283. [CrossRef]

57. Hou, J.; Hu, M.; Zhang, L.; Gao, Y.; Ma, L.; Xu, Q. Dietary Taxifolin Protects Against Dextran Sulfate Sodium-Induced Colitis via NF-кB Signaling, Enhancing Intestinal Barrier and Modulating Gut Microbiota. Front. Immunol. 2020, 11, 631809. [CrossRef] [PubMed]

58. Famurewa, A.C.; Ejezie, A.J.; Ugwu-Ejezie, C.S.; Ikekpeazu, E.J.; Ejezie, F.E. Antioxidant and anti-inflammatory mechanisms of polyphenols isolated from virgin coconut oil attenuate cadmium-induced oxidative stress-mediated nephrotoxicity and inflammation in rats. J. Appl. Biomed. 2018, 16, 281-288. [CrossRef]

59. Yeo, S.C.M.; Fenwick, P.S.; Barnes, P.J.; Lin, H.S.; Donnelly, L.E. Isorhapontigenin, a bioavailable dietary polyphenol, suppresses airway epithelial cell inflammation through a corticosteroid-independent mechanism. Br. J. Pharmacol. 2017, 174, 2043-2059. [CrossRef]

60. Grun, C.H.; van Dorsten, F.A.; Jacobs, D.M.; Le Belleguic, M.; van Velzen, E.J.; Bingham, M.O.; Janssen, H.G.; van Duynhoven, J.P. GC-MS methods for metabolic profiling of microbial fermentation products of dietary polyphenols in human and in vitro intervention studies. J. Chromatogr. B Anal. Technol. Biomed. Life Sci. 2008, 871, 212-219. [CrossRef] [PubMed]

61. Soleha, M.; Pratiwi, D.E.; Sari, I.D.; Hermiyanti, E.; Yunarto, N.; Setyorini, H.A. Antioxidant Activity of Methanol Extract Tetracera scanden L Merr Predicted Active Compound of Methanol Extract with GCMS NIST Library. J. Phys. Conf. Ser. 2020, 1665, 012028. [CrossRef]

62. Fernando, I.P.S.; Sanjeewa, K.K.A.; Lee, H.G.; Kim, H.S.; Vaas, A.; De Silva, H.I.C.; Nanayakkara, C.M.; Abeytunga, D.T.U.; Lee, D.S.; Lee, J.S.; et al. Fucoidan Purified from Sargassum polycystum Induces Apoptosis through Mitochondria-Mediated Pathway in HL-60 and MCF-7 Cells. Mar. Drugs 2020, 18, 196. [CrossRef] [PubMed]

63. Kamada, T.; Kang, M.C.; Phan, C.S.; Zanil, I.I.; Jeon, Y.J.; Vairappan, C.S. Bioactive Cembranoids from the Soft Coral Genus Sinularia sp. in Borneo. Mar. Drugs 2018, 16, 99. [CrossRef]

64. Han, L.; Du, L.B.; Kumar, A.; Jia, H.Y.; Liang, X.J.; Tian, Q.; Nie, G.J.; Liu, Y. Inhibitory effects of trolox-encapsulated chitosan nanoparticles on tert-butylhydroperoxide induced RAW264.7 apoptosis. Biomaterials 2012, 33, 8517-8528. [CrossRef] [PubMed]

65. Spencer, D.M.; Gauley, J.; Pisetsky, D.S. The properties of microparticles from RAW 264.7 macrophage cells undergoing in vitro activation or apoptosis. Innate Immun. 2014, 20, 239-248. [CrossRef] [PubMed]

66. Song, J.; Zhang, J.; Su, Y.; Zhang, X.; Li, J.; Tu, L.; Yu, J.; Zheng, Y.; Wang, M. Monascus vinegar-mediated alternation of gut microbiota and its correlation with lipid metabolism and inflammation in hyperlipidemic rats. J. Funct. Foods 2020, $74,104152$. [CrossRef] 